\title{
Kinematic cervical rotation performance in patients with acute non-specific neck pain during the DidRen test improves after manual mobilizations regardless of the painful spinal level
}

Renaud Hage ( $\nabla$ renaud.hage@uclouvain.be )

UCLouvain

Christine Detrembleur

UCLouvain

Frédéric Dierick

Centre National de Rééducation Fonctionnelle et de Réadaptation

Jean-Michel Brismée

Texas Tech University Health Sciences Center

Nathalie Roussel

University of Antwerp

Laurent Pitance

UCLouvain

\section{Research Article}

Keywords: Cervical rotation, sensorimotor assessment, acute non-specific neck pain, passive mobilizations

Posted Date: April 28th, 2021

DOI: https://doi.org/10.21203/rs.3.rs-403229/v1

License: (c) (1) This work is licensed under a Creative Commons Attribution 4.0 International License. Read Full License 


\section{Abstract}

Background: Evaluation of kinematic axial cervical rotation performance is of major importance in the context of studying sensorimotor control of the neck. However, studies are missing on acute neck pain, on the influence of the level of provocation of spinal pain, and on the potential benefits of manual therapy mobilizations.

Methods: A non-randomized prospective trial with intervention assessed the influence of acute nonspecific neck pain on kinematic parameters during a fast axial head rotation task standardized with the DidRen laser test device. First, we compared kinematic parameters between patients and healthy controls. Second, we assessed whether upper or lower spinal pain location influenced these kinematic parameters. Finally, we examined the short-term effect of passive cervical mobilizations in patients on these kinematic variables.

Results: We observed that patients were significantly slower (total time) to perform the DidRen laser test (4.5s; $p<0.006)$ and to reach the end of rotation from peak acceleration $(0.02 s ; p<0.016)$. The time between peaks acceleration and deceleration $(-0.03 \mathrm{~s} ; p<0.003)$, the time to peak deceleration $(0.004 \mathrm{~s}$; $p<0.003)$, to peak acceleration ( $0.04 \mathrm{~s} ; p<0.001)$ and to peak speed $(0.01 \mathrm{~s} ; \mathrm{p}<0.001)$, the average speed $\left(7.2^{\circ} \mathrm{s}^{-1} ; p<0.001\right)$, peak speed $\left(21.7^{\circ} \mathrm{s}^{-1} ; p<0.010\right)$, acceleration $\left(143.5^{\circ} \mathrm{s}^{-2} ; p<0.013\right)$ and deceleration $\left(-193.1^{\circ} s^{-2} ; p<0.006\right)$ were significantly slower for patients compared to controls. No significant effect of spinal pain location was observed on kinematic variables. After the intervention, patients were faster for average speed $\left(2.9^{\circ} \mathrm{s}^{-1} ; p<0.02\right)$, peak speed $\left(8.7^{\circ} \mathrm{s}^{-1} ; p<0.011\right)$, peak deceleration $\left(69.7^{\circ} \mathrm{s}^{-2} ; p<0.007\right)$. Patients took less time to reach peak speed $(0.01 \mathrm{~s} ; p<0.033)$ and peak acceleration $(0.01 \mathrm{~s} ; p<0.028)$. They took also less time $(-0.01 \mathrm{~s} ; p<0.003)$ between peak acceleration and deceleration and to stabilize the laser into the target $(0.12 s ; p<0.026)$ and to perform the DidRen laser test $(4 s ; p<0.001)$.

Conclusion: The DidRen laser test allowed to demonstrate significant differences in kinematic axial cervical rotation in patients suffering from acute non-specific neck pain compared to pain-free controls. No significant effect of spinal pain location was observed on kinematic variables. Pain reduction significantly improved the patients' kinematic parameters.

\section{Introduction}

About $50 \%$ of the population will experience neck pain at least once in their lifetime, with women being more at risk than men [1]. Neck pain is a major health care cost and the fourth largest cause of disability [2] and in second place in selected countries behind low back pain [3].

Most patients with neck pain are nowadays classified as "non-specific" neck disorders [4-6]. As the primary purpose of a diagnosis and a classification system is to predict and offer the best therapeutic approach [7], this classification does not help clinician in their clinical reasoning to understand the contributing factors to the patient's pain and dysfunction. 
The "non-specific" is defined as neck pain occurring in the absence of trauma, signs or symptoms of major structural pathology, neurological signs, or specific pathology [4]. Degenerative changes in the joints, muscles and psychosocial stress in many patients with non-specific cervical pain can alter cervical somatosensory inputs, which lead to functional modifications as lack of stability and impaired kinematic control. Somatosensory inputs from mechanoreceptors found in muscles, tendons, ligaments and capsules, are transmitted to the brain. This transmission of information contributes to the cortical representation of pain [8-10].

For the clinician that needs to manage the pain of the patient, there are therefore specific issues in patients with non-specific neck pain. Classifying patients with neck pain into specific and non-specific categories is certainly a first step in the process of clinical reasoning. But this classification alone does not permit to establish a full treatment plan. Hence the importance of history taking and a thorough clinical examination of the patient to steer the clinical reasoning process. Clinical guidelines for the management of patients with neck pain, as recommended by the orthopedic section of the American Physical Therapy Association (APTA), adopt a classification system linked to the International Classification of Function impairments (ICF) of body functions terminology [4] They also recommend to include the assessment of range of motion and response to pain [11, 12]. Nevertheless, in order to obtain a more complete clinical picture of a patient with neck pain during movements, other objective observations such as the quality of movement (i.e., sensorimotor appraisal) are essential.

Clinicians show increased interest in different tests in an attempt to better define the clinical picture of patients by focusing on sensorimotor control assessment during head axial rotation [13-19]. Calculating head repositioning error, measuring the accuracy of the ability to follow a virtual target or assessing accurate fast head axial rotational in response to real visual targets are all possible evaluations of cervical sensorimotor control $[18,20,21]$. The DidRen laser is a functional test consisting of standardized task with "target-to-target" axial head rotations carried out in the same order. It consists of fast, low amplitude and accurate head axial rotational movements in response to real visual targets that must be hit by a laser beam placed on the individuals' head [21-23]. This test is particularly useful as it focuses on the neck sensory and motor control systems with many direct neurophysiological connections between the proprioceptive, visual and vestibular systems [8]. By limiting the range of head rotation at $30^{\circ}$ [24], it avoids the neck passive system strain (joint capsules, facet joints, intervertebral disks and ligaments) and focuses on input from the upper cervical proprioceptive system, which is highly developed in the sub-occipital upper neck region $[25,26]$ corresponding to the spinal muscles that provides dynamic stability during the first degrees of rotation [24].

The majority of sensorimotor control studies have been conducted on chronic neck pain patients [27-29]. Nevertheless, there is some evidence that sensorimotor control deficits can occur very soon after the onset of neck pain [29]. This has for example been demonstrated in patients after an acute whiplash trauma [29]. Moreover, we do not yet know about the quality of movement (i.e., in terms of kinematic strategies) measured with the DidRen test on neck pain patients and whether there were kinematic differences compared to healthy controls. Although there is some evidence suggesting that sensorimotor 
disturbances would be more important in participants with chronic neck pain originating from upper cervical levels $\left(C_{0}\right.$ to $\left.C_{2}\right)$ compared to lower cervical levels $\left(C_{3}\right.$ to $\left.C_{7}\right)[30,31]$, to our knowledge, studies assessing sensorimotor disturbances in acute neck pain patients and the potential influence of the level of spinal pain provocation are missing.

A growing body of research shows the effects of spinal manipulations on sensory processing, motor power, functional performance, sensorimotor integration [30,31] and pain relief [32, 33]. However, studies assessing the potential benefits of passive manual mobilization on changes in sensorimotor control in acute neck pain patients are lacking.

A non-randomized prospective trial with intervention was designed to examine the influence of pain on kinematic variables (i.e. angular displacement and its derivatives) [22], during a fast head axial rotation task standardized with the DidRen laser test device in patients with acute non-specific neck pain and healthy pain-free control subjects.

We hypothesize that patients suffering from neck pain (1) and in particular pain located in the upper cervical region (2) would have significantly impaired kinematic parameters compared to healthy controls. We further hypothesize a restoration will take place after relieving the pain using Maitland's passive accessory neck mobilizations (3) [34-37].

\section{Methods}

\section{Study design}

The present study entails a non-randomized prospective trial with intervention (Fig 1).

\section{Participants}

Patients with acute non-specific neck pain were consecutively recruited from a private manual physiotherapy center from February to December 2019 as sample of convenience. Inclusion criteria were acute (<3months) non-specific neck pain with a neck disability index (NDI) > 8\% [38] and a Numerical Pain Rating Scale (NPRS) >3 [39]. Patients were excluded if they reported any of the following: a history of neck surgery, dizziness caused by neck or head movements [40] and cervical radiculopathy diagnosed by a physician [41]. Healthy pain-free control participants recruited consecutively from a sample of convenience from colleagues in University hospital and among researchers' acquaintances volunteered to participate in this study. They were included if they reported a NDI $<8 \%$ [38] and a NPRS $=0$ [39]. Manual spinal examination for segmental tenderness is known to have a high sensitivity (92\%), so this was used to include healthy pain-free controls without neck pain [42]. Participants were excluded if they reported neck pain during the last year, radiating symptoms in the shoulder or upper limb regions, or headache. Participants with a history of neck trauma or in therapy for spinal disorders [40] or reporting pain during active head rotation or manual spinal assessment were excluded as well [42]. 
All participants signed an informed consent, the study was approved by the Comité Académique de Bioéthique (Brussels, B200-2018-103) and conducted in accordance with the declaration of Helsinki. The authors confirm that all ongoing and related trials for this drug/intervention are registered (ClinicalTrials.gov: 04407637).

At baseline, patients were asked to fill in the following questionnaires: the French version of the NDI, the French version of the Bournemouth questionnaire (BQ) [43], the French version of the Tampa scale of Kinesiophobia (TSK) [44] and a NPRS. Healthy controls were asked to fill the NDI, the BQ and the NPRS.

The NDI is a self-rated questionnaire assessing disability due to neck pain, which consist of a series of 10 questions on activities relating to daily living all assessed on a 6-point scale. Each item is rated out of 5 for a maximum total score of 50 or as a percentage out of 100 . The interpretation of the NDI notation (in $\%$ ), is as follows: $0-8=$ none; $10-28=$ mild; $30-48=$ moderate; $50-68=$ severe; more than $68=$ complete [45].

The $\mathrm{BQ}$ is based on the biopsychosocial model to evaluate different dimensions in neck pain participants including the pain, disability, affective and cognitive aspects of neck pain. Each question (7 items) is scored on an eleven-point (0-10) numerical rating scale. The maximum score for the BQ is 70 points, obtained by summing the scores for each of the seven items [43].

The TSK is a 17-item questionnaire used to assess fear of movement or reinjury, in which participants are asked to rate their level of agreement with each item on a 1 (strongly disagree) to 4 (strongly agree) scale. The TSK has been shown to be associated with measures of behavioral avoidance and self-reported disability. A cut-off of 39 is associated with a risk for prolonged pain-related disability [46].

The NPRS is a commonly used outcome to assess patients with neck pain. It uses an 11-point scale, ranging from 0 (no pain) to 10 (worst pain imaginable) [39].

\section{Procedures}

After completing questionnaires, patients were assigned to examination phases of the spinal region, which included the assessment of fast neck rotation with the DidRen laser test, the active cervical rotation range of motion and the manual examination. After the examination phase, the patient was assigned to the intervention phase. Note that the DidRen laser test was evaluated by another assessor.

After the filling of questionnaires, healthy participants were assigned to examination phases. Reliability of the DidRen laser test and the active cervical rotation range of motion was assessed for healthy controls. It allowed us to calculate the intra-class coefficient correlation, the standard error of measurement and the minimal detectable change.

\section{Examination phases}


For blinding purposes, a physiotherapy assessor, familiar with the use of DidRen, completed the DidRen laser test and active cervical rotation range of motion testing. Cervical examination and physiotherapy treatments were conducted by a second assessor $(\mathrm{RH})$ with 20 years of experience as certified orthopaedic manual physiotherapist and with 15 years of experience as teacher of orthopaedic manual therapy.

\section{DidRen laser test and computed kinematic variables}

The DidRen laser test was used to homogenize the rotational motion of the participant's head-neck complex as in previous published papers (Hage \& Ancenay 2009; Hage et al. 2019a; Hage et al. 2019b). In summary, participants wore a helmet on which a laser was attached. They directed the laser as fast as possible on three targets equipped with photosensitive sensors (Fig $2 \mathrm{~A}$ ). To obtain a head rotation of maximum $30^{\circ}$, sensors are spaced apart and located in front of them at a distance of $90 \mathrm{~cm}$ (Fig $2 \mathrm{~B}$ ).

During the DidRen laser test, the axial head rotation was recorded using a validated inertial motion unit sensor, the DYSKIMOT (Hage et al. 2020). The detailed description of the DYSKIMOT sensor is available in the study of Hage et al. (2020). The DYSKIMOT, placed on the front of the helmet, recorded the motion with a sampling frequency of $100 \mathrm{~Hz}$ (Fig $2 \mathrm{C}$ ).

To determine the number of repetitions required to familiarize the patient/healthy control with the test, we completed an unpublished pilot study to test 7 healthy subjects. Following our results, we were able to highlight the need to have the DidRen Laser test performed 4 times. We recorded the fourth test outcome for the results.

Head angular displacement, speed and acceleration were recorded in 3D by the DYSKIMOT. Kinematic data were analyzed as previously described in Hage et al. (2019) and illustrated in Figure 3 (Hage et al. 2019a). As described in Hage et al. (2019), the DidRen total time (in s) was also calculated as the total time taken by the participants to complete the 5 cycles of one trial (Hage et al. 2019a; Hage et al. 2019b).

\section{Active cervical rotation range of motion (ROM)}

The mean of three active ROM was measured using the DYSKIMOT device [47]: participants were asked to rotate their head and neck as far as possible. During active cervical ROM measurements, participants were asked to report any familiar pain on a NPRS (0-10).

\section{Cervical manual examination}

To determine the most symptomatic segment(s), patients underwent a manual cervical examination by $\mathrm{RH}$. Based exclusively on this examination, participants were assigned either to the upper $\left(\mathrm{C}_{0}-\mathrm{C}_{2}\right)$ or lower $\left(C_{3}\right.$ to $\left.C_{7}\right)$ spinal pain group. The spinal manual examination included the $C_{0}-C_{2}$ axial rotation test, the passive physiological intervertebral movements (PPIVM's) and the passive accessory intervertebral movements (PAIVM's) [41, 48]. 
$\mathrm{C}_{0}-\mathrm{C}_{2}$ axial rotation test was performed to detect the presence or absence of superior cervical joint impairment in rotation. $\mathrm{C}_{0}-\mathrm{C}_{2}$ axial rotation test has demonstrated high intra- and inter-examiner reliability on normal subjects [49] and high inter-examiner reliability on patients with neck pain [50]. For this test, the patient was examined in a standardized sitting position with the neck in neutral position. The assessor passively rotated the patient's head to the right and left with $\mathrm{C}_{2}$ stabilized with the assessor's thumb and index fingers to isolate superior cervical levels from below (Fig 4). Interestingly, the $C_{0}-C_{2}$ axial rotation test is designed to evaluate the rotation of levels from the occiput to $C_{1}$ and from $C_{1}$ to $C_{2}$. But the rotation of $C_{1}$ in relation to the occiput is only $1^{\circ}$ [51]. Therefore, in order to assess the $C_{0}-C_{1}$ level and the upper cervical levels in other ranges than only rotation, we used the PPIVM's in extension/lateral flexion. PPIVM's are designed to assess segmental cervical spine movement, but to our knowledge, reliability of PPIVM's has never been assessed [48]. For PPIVM's, the patient laid supine so the assessor could move passively each patient's neck level in extension/lateral flexion, from the upper cervical region $\mathrm{C}_{0-1}, \mathrm{C}_{1-2}$ to the lower region $\mathrm{C}_{6-7}$ on each side (Fig 5). PAIVM's were performed to detect the presence or absence of cervical joint dysfunction [41, 52]. PAIVM's have demonstrated moderate to excellent intra- and interexaminer reliability in patients with neck pain [41]. For PAIVM's, the assessor applied his thumbs centrally directed posterior-anterior (central $P / A$ ) force toward the spinous process or unilaterally posterior-anterior directed force to the articular pillars (unilateral P/A) from the upper cervical region $\mathrm{C}_{0-1}, \mathrm{C} 1-2^{2}$ to the lower region $\mathrm{C}_{6-7}$ on each side (Fig 6).

Any perceived resistance by the assessor to passive motion: $\mathrm{C}_{0}-\mathrm{C}_{2}$ axial rotation test, PPIVM's and PAIVM's, was subjectively recorded as slight, moderate, marked [53]. The patient was asked to report any familiar pain provocation on NPRS (1-10) [54].

Positive tests at the upper levels were defined as reports of familiar local pain with PAIVM's when the assessor rated stiffness to passive motion with $\mathrm{C}_{0}-\mathrm{C}_{2}$ axial rotation test and/or PPIVM's.

Positive tests at the lower levels (below $\mathrm{C}_{2}$ ) were defined as reports of familiar local pain with PAIVM's when the assessor rated stiffness to passive motion with PPIVM's.

Based on these findings, participants entered either in the upper or lower cervical region group.

\section{Intervention phase}

Patient's intervention (i.e. physiotherapy treatment) included PAIVM's mobilizations [34, 37]. As evidence exists showing that changes in motor function occur as a result of a specific mode of training [55], we tried to avoid and prevent direct influence on sensorimotor system and the DidRen laser test during intervention phase. To do so, neither cervical muscle strength-endurance nor functional strength [56] nor sensorimotor control tests (e.g. cervical repositioning, oculomotor exercises [8]) or head rotation were carried out during intervention. Pragmatically, PAIVM's were performed on spinal level(s), which were recorded as painful sites during the first spinal examination and/or based on decision-making process 
(clinical reasoning) throughout the different therapy sessions of the physiotherapist [34, 37, 57]. PAIVM's were performed either central posterior-anterior with directed force toward the spinous process or a unilateral posterior-anterior with force directed to the articular pillars [34, 37, 57]. Mobilization grades 1,2 , 3 , or 4 were selected according to patient tolerance and clinical reasoning $[34,37,57]$ i.e. specific number of sets, repetitions and the dose of the mobilization were left to the therapist's interpretation, exactly as in clinical settings.

When patient's pain had returned to what he considered as normal (before her/his acute neck pain), last intervention was carried out.

After the last mobilizations session, patients were immediately assessed for fast neck rotation using the DidRen laser test and cervical ROM testing by the first assessor. NPRS was also reassessed.

\section{Statistical analyses}

For each kinematic parameter, the reliability between the first $\left(T_{1}\right)$ and second $\left(T_{2}\right)$ DidRen laser tests of the healthy control group was assessed. Each parameter was the result of the average of the 5 cycles performed by each healthy control subject.

The reliability was then calculated with the intra-class correlation coefficient (ICC). We used intra-rater reliability with two trials $\left(\mathrm{ICC}_{3,2}\right)$ [58] and with a 2-way random with absolute agreement [59]. ICCs were calculated for each kinematic parameters with a 95\% confidence interval $(95 \% \mathrm{Cl})$ [60]. The guidelines used for the interpretation of ICC results were the following: a moderate ICC when greater than 0.40 and an excellent ICC when greater than 0.80 [60].

Thanks to ICC, the agreement was calculated by the standard error measurement (SEM), SEM = $S D \gamma \sqrt{(1-R \gamma)}$, where $S D \gamma=$ standard deviation of $\gamma=$ average of results of $\mathrm{T}_{1}$ and $\mathrm{T}_{2}$, and $R \gamma=\mathrm{ICC}$ between $T_{1}$ and $T_{2}$. Standard measurement errors were also calculated in percentage relative to the mean, as follow: $R S E M \%=\frac{S E M}{M E A N} \times 100$, where $M E A N=$ average of all observations of $\mathrm{T}_{1}$ and $\mathrm{T}_{2}$.

Thanks to the SEM, the minimum detectable change (MDC) at $95 \%$ CI level $\left(M D C_{95}\right)$ was also computed as $M D C_{95}=1.96 \times \sqrt{2 \times S E M}$. MDC was also calculated in percentage relative to the mean, as follow $R M D C \%$ $=\frac{M D C}{M E A N} \times 100$, where $M E A N=$ average of all observations of $\mathrm{T}_{1}$ and $\mathrm{T}_{2}$.

As the males/female's balance was not optimal, the effect of gender (gender $x$ groups) on kinematic variables was assessed. We used a two-way ANOVA with post hoc Holm-Sidak method for pairwise multiple comparisons when ANOVA indicated significant interaction.

Given the age difference between patients and healthy participants, we compared our healthy group to the older group using the normative data of Hage et al. ( $n=47$, ranging from $24 \pm 3$ years to $53 \pm 7$ years) 
[23]. We used a one-way ANOVA to compare the DidRen total time results which proved to be the most age-sensitive variable for the DidRen laser test [22].

Patient's data were compared to healthy control group (before and after intervention) by a Student $\mathrm{t}$ test or Kruskall Wallis test (if normality failed). Post-hoc Holm-Sidak method for pairwise multiple comparisons was carried out when the data were normally distributed and with post hoc Dunn's method for pairwise multiple comparisons if normality test failed.

To assess the effect of the painful cervical level (upper/lower) and the variation in the experienced pain after the mobilization's intervention on the kinematic variables, a two-way repeated measure ANOVA with post hoc Holm-Sidak method for pairwise multiple comparisons was conducted when ANOVA indicated significant interaction.

The effect of post-intervention experienced pain variation for each kinematic variable for all patients (upper and lower cervical levels) was calculated with a paired-t test. Wilcoxon signed rank test was carried out when normality test failed.

ICC calculation was done with IBM SPSS Statistics-25. All others statistical procedures were performed with SigmaPlot 13 (Systat Software, Inc) with a significant level set at 0.05.

Effect sizes (ES) were calculated with the goal of moving away from the relevance of statistical significance to a more interpretable quantitative description of the size of the effect [61] that indicated the strength of a hypothetical effect. The size of the intervention effect for kinematic variables was calculated using the formula:

$d=\frac{\text { mean }_{t 2}-\text { mean }_{t 1}}{S D_{\text {pooled }}}$. Interpretation of the ES was: low (0.2-0.5), medium (0.5-0.8) and large $(>0.8)[61]$.

Sample size was calculated only for the DidRen total time. First, it is the only kinematic variable that has ever been studied in a neck pain population [21]. Second, this kinematic variable was considered by Hage et al. as the most relevant outcome for the DidRen laser test [22]. For the effect of pathology (difference between patients and healthy controls), the sample size was determined at 37 individuals in each group with two-sample t-tests assuming equal variance. For the effect of the intervention (difference between before and after mobilizations), a sample size of 20 individuals was estimated for a Paired T-Test. For both, the power was $85 \%$ with $\alpha$ at 0.05 , the mean difference was determined at 5.0 seconds and the standard deviation at 7.0 for each group. Our sample size calculation was in accordance with the study of Bahat et al. [17].

\section{Results}

Forty-two patients were screened but 4 patients were excluded because they canceled their second appointment, so they were only seen at $T_{1}$. Fifty controls were screened but 12 participants were excluded 
because they were not pain-free (i.e. they experienced pain during passive manual assessment of the cervical spine).

Hence, a total of 38 patients and 42 healthy controls participated in the study. Table 1 presents patient and healthy control groups characteristics. Table 2 presents clinical information collected before and after the mobilizations.

Table 1

Characteristics of the patients and controls

\begin{tabular}{|c|c|c|c|}
\hline Global $(n=80)$ & Patients $(n=38)$ & $\begin{array}{l}\text { Healthy Controls }(n= \\
\text { 42) }\end{array}$ & $P$-values \\
\hline Age (years), mean \pm SD & $46.2 \pm 16.3$ & $24.3 \pm 6.8$ & $<0.001$ \\
\hline Sex n (males/females), (\%) & $21(55 \%) / 17(45 \%)$ & $27(64 \%) / 15(36 \%)$ & 0.55 \\
\hline $\mathrm{BMI}\left(\mathrm{kg} \mathrm{m}^{-2}\right)$, mean $\pm \mathrm{SD}$ & $23.5 \pm 3.2$ & $21.5 \pm 4.2$ & 0.014 \\
\hline NDI (100), median [Q1-Q3] & 22 [16-31.5] & $0[0-0]$ & $<0.001$ \\
\hline NPRS, median [Q1-Q3] & $6[4-7]$ & $0[0-0]$ & $<0.001$ \\
\hline $\begin{array}{l}\text { Active Rotation: Left (SD) - } \\
\text { Right (SD) }\end{array}$ & $\begin{array}{l}59.1^{\circ}\left(16.7^{\circ}\right)-59.7^{\circ} \\
\left(13.6^{\circ}\right)\end{array}$ & $\begin{array}{l}69.7^{\circ}\left(8.2^{\circ}\right)-70.4^{\circ} \\
\left(6.8^{\circ}\right)\end{array}$ & $\begin{array}{l}0.019 \\
0.014\end{array}$ \\
\hline TSK median [Q1-Q3] & 38 [31-42] & Not applicable & $\begin{array}{l}\text { Not } \\
\text { applicable }\end{array}$ \\
\hline Bournemouth, median [Q1-Q3] & 28.5 [15.25-46] & $2.1[0-2.75]$ & $<0.001$ \\
\hline
\end{tabular}


Table 2

Patients' clinical information before and after the mobilizations

\begin{tabular}{|c|c|c|c|}
\hline Patients $(n=38)$ & $\begin{array}{l}\text { Before } \\
\text { mobilizations }\end{array}$ & $\begin{array}{l}\text { After } \\
\text { mobilizations }\end{array}$ & $P$-values \\
\hline NPRS, median [Q1-Q3] & $6[4-7]$ & $0[0-1]$ & $<0.001$ \\
\hline Number of patients, with (Upper/Lower) pain location & $(17 / 21)$ & $\begin{array}{l}\text { Not } \\
\text { applicable }\end{array}$ & $\begin{array}{l}\text { Not } \\
\text { applicable }\end{array}$ \\
\hline NPRS, due to DidRen laser test [Q1-Q3] & $2[0-4.75]$ & $0[0-0]$ & $<0.001$ \\
\hline Upper neck NPRS during DidRen laser test [Q1-Q3] & $1.5[0-4]$ & $0[0-0]$ & $<0.001$ \\
\hline Lower neck NPRS during DidRen laser test [Q1-Q3] & $2[0-4.25]$ & $0[0-0]$ & $<0.001$ \\
\hline $\begin{array}{l}\text { Number of patients who took pain medication }(n) \text { : } \\
\text { NSAID; Paracetamol; Pain Killer }\end{array}$ & (7); (4); (1) & $(0),(0),(0)$ & $\begin{array}{l}\text { Not } \\
\text { applicable }\end{array}$ \\
\hline Number of sessions, mean (SD) & $\begin{array}{l}\text { Not } \\
\text { applicable }\end{array}$ & $4.7(2.3)$ & $\begin{array}{l}\text { Not } \\
\text { applicable }\end{array}$ \\
\hline Number of weeks for therapy (SD) & $\begin{array}{l}\text { Not } \\
\text { applicable }\end{array}$ & $6(3.5)$ & $\begin{array}{l}\text { Not } \\
\text { applicable }\end{array}$ \\
\hline
\end{tabular}

There were no significant differences for interaction between gender and groups (see supplemental Table 1).

No significant kinematic differences were observed between the healthy control group compared to the normative data of Hage et al. [23] .

ICC values for kinematic parameters are presented in Table 4. All ICCs ranged from moderate to excellent, except for overshoot (0.08) and time to peak deceleration (0.22). However, the $95 \% \mathrm{Cl}$ of the low and moderate ICCs indicates that the results were not homogeneous, with a high inter-subject group variability.

No significant differences were observed between patients with upper versus lower spinal pain location (see supplemental Table 2). Hence, patients were considered as one group in further analyses.

Results showing the difference between patients and healthy controls are presented in Table 3. Patients were significantly slower (total time) than healthy controls to perform the DidRen laser test (4.5 $\mathrm{s} ; p<$ $0.006)$, and to reach the end of rotation from peak acceleration $(0.02 s ; p<0.016)$. Average speed $\left(7.2^{\circ} \mathrm{s}^{-}\right.$ $1 ; p<0.001)$, peak speed (21.7 $\left.{ }^{\circ} \mathrm{s}^{-1} ; p<0.010\right)$, peak acceleration $\left(143.5^{\circ} \mathrm{s}^{-2} ; p<0.013\right.$ ) and deceleration $\left(-193.1^{\circ} \mathrm{s}^{-2} ; p<0.006\right)$ were significantly slower for patients compared to healthy controls. Patients were also slower for time to peak speed $(0.01 \mathrm{~s} ; p<0.001)$, to peak acceleration $(0.04 \mathrm{~s} ; p<0.001)$ and 
deceleration $(0.004 s ; p<0.003)$ and time between peaks acceleration and deceleration $(0.03 s ; p<0.003)$. Only the latter four variables remained significantly different after the completion of intervention.

Pre- and post-intervention results by status are reported in supplemental Table 3.

Observed differences between patients and healthy controls were always larger than the SEM but smaller than the MDC. 
Table 3

Results for kinematic variables during the DidRen laser test based on the comparison of patients and healthy controls before the intervention. Intraclass correlation coefficient, Standard Error of Measurement and Minimal Detectable Change obtained from controls are given for comparison with the patients' data.

\begin{tabular}{|c|c|c|c|c|c|}
\hline Variables & $\begin{array}{l}\text { Difference of } \\
\text { the means }\end{array}$ & $\begin{array}{l}P \\
\text { values }\end{array}$ & $\begin{array}{l}\text { ICC }(95 \% \\
\mathrm{Cl})\end{array}$ & $\begin{array}{l}\text { SEM } \\
\text { (RSEM\%) }\end{array}$ & $\begin{array}{l}\text { MDC } \\
\text { (RMDC\%) }\end{array}$ \\
\hline ROM test $\left({ }^{\circ}\right)$ & 0.25 & 0.859 & $\begin{array}{l}0.57 \\
(0.06- \\
0.80)\end{array}$ & $\begin{array}{l}0.58 \\
(-2.14)\end{array}$ & $\begin{array}{l}1.60 \\
(-5.93)\end{array}$ \\
\hline Average speed $\left({ }^{\circ} s^{-1}\right)$ & 7.16 & $\hat{0.001 * *}$ & $\begin{array}{l}0.84 \\
(0.65- \\
0.92)\end{array}$ & $\begin{array}{l}3.44 \\
(7.17)\end{array}$ & $\begin{array}{l}9.53 \\
(19.89)\end{array}$ \\
\hline Peak speed $\left({ }^{\circ} s^{-1}\right)$ & 21.68 & 0.010 * & $\begin{array}{l}0.93 \\
(0.85- \\
0.97)\end{array}$ & $\begin{array}{l}8.26 \\
(7.39)\end{array}$ & $\begin{array}{l}22.91 \\
(20.48)\end{array}$ \\
\hline Peak acceleration $\left({ }^{\circ} s^{-2}\right)$ & 143.48 & 0.013 * & $\begin{array}{l}0.95 \\
(0.89- \\
0.97)\end{array}$ & $\begin{array}{l}75.65 \\
(12.96)\end{array}$ & $\begin{array}{l}209.69 \\
(35.93)\end{array}$ \\
\hline Peak deceleration $\left({ }^{\circ} s^{-2}\right)$ & -193.13 & $0.006 *$ & $\begin{array}{l}0.96 \\
(0.91- \\
0.98)\end{array}$ & $\begin{array}{l}71.12 \\
(-8.07)\end{array}$ & $\begin{array}{l}197.13 \\
(-22.38)\end{array}$ \\
\hline Time to peak speed (s) & 0.01 & $<.001^{\star *}$ & $\begin{array}{l}0.61 \\
(0.17- \\
0.82)\end{array}$ & $\begin{array}{l}0.02 \\
(14.86)\end{array}$ & $\begin{array}{l}0.044 \\
(41.18)\end{array}$ \\
\hline Time to peak acceleration (s) & 0.04 & $<.001 * *$ & $\begin{array}{l}0.81 \\
(0.60- \\
0.91)\end{array}$ & $\begin{array}{l}0.02 \\
(10.05)\end{array}$ & $\begin{array}{l}0.05 \\
(27.84)\end{array}$ \\
\hline Time to peak deceleration (s) & 0.004 & $0.003^{*}$ & $\begin{array}{l}0.22 \\
(-0.65- \\
0.63)\end{array}$ & $\begin{array}{l}0.02 \\
(30.43)\end{array}$ & $\begin{array}{l}0.05 \\
(84.35)\end{array}$ \\
\hline $\begin{array}{l}\text { Time between peaks } \\
\text { acceleration-deceleration (s) }\end{array}$ & -0.03 & $0.003^{\star}$ & $\begin{array}{l}0.78 \\
(0.53- \\
0.89)\end{array}$ & $\begin{array}{l}0.01 \\
(-13.01)\end{array}$ & $\begin{array}{l}0.04 \\
(-36.09)\end{array}$ \\
\hline $\begin{array}{l}\text { Time from peak acceleration to } \\
\text { end of rotation (s) }\end{array}$ & 0.02 & $0.016 *$ & $\begin{array}{l}0.44 \\
(-0.21- \\
0.74)\end{array}$ & $\begin{array}{l}0.02 \\
(15.76)\end{array}$ & $\begin{array}{l}0.06 \\
(43.68)\end{array}$ \\
\hline
\end{tabular}

$P$-values are given for the differences between patients and controls. $P$-Values in bold means that significant difference observed before the intervention are not significant after it, indicating some return to normality. ${ }^{*} p<0.05$. ${ }^{*} p<0.001$. ICC $=$ Intraclass Correlation Coefficient. Cl: Confidence Interval. SEM = Standard Error of Measurement. RSEM\%= Relative (\%) Standard Error of Measurement expressed as a percentage. MDC = Minimal Detectable Change. \%RMDC = Relative (\%) Minimal Detectable Change expressed as a percentage. Be careful not to confuse this ROM test (which is the ROM reached during the DidRen laser test) and active ROM (performed by the patient before the DidRen laser test). 


\begin{tabular}{|c|c|c|c|c|c|}
\hline Variables & $\begin{array}{l}\text { Difference of } \\
\text { the means }\end{array}$ & $\begin{array}{l}P \\
\text { values }\end{array}$ & $\begin{array}{l}\text { ICC }(95 \% \\
\mathrm{Cl})\end{array}$ & $\begin{array}{l}\text { SEM } \\
\text { (RSEM\%) }\end{array}$ & $\begin{array}{l}\text { MDC } \\
\text { (RMDC\%) }\end{array}$ \\
\hline Angle at maximum speed $\left(^{\circ}\right)$ & 0.13 & 0.553 & $\begin{array}{l}0.66 \\
(0.27- \\
0.84)\end{array}$ & $\begin{array}{l}0.82 \\
(5.74)\end{array}$ & $\begin{array}{l}2.27 \\
(15.91)\end{array}$ \\
\hline Stabilisation Time (s) & 0.14 & 0.078 & $\begin{array}{l}0.79 \\
(0.45- \\
0.91)\end{array}$ & $\begin{array}{l}0.14 \\
(8.25)\end{array}$ & $\begin{array}{l}0.39 \\
(22.87)\end{array}$ \\
\hline Overshoot $\left({ }^{\circ}\right)$ & 0.05 & 0.278 & $\begin{array}{l}0.08 \\
(-1.02- \\
0.57)\end{array}$ & $\begin{array}{l}0.22 \\
(35.51)\end{array}$ & $\begin{array}{l}0.62 \\
(98.44)\end{array}$ \\
\hline DidRen time (s) & 4.55 & $0.006 *$ & $\begin{array}{l}0.78 \\
(0.31- \\
0.91)\end{array}$ & $\begin{array}{l}2.74 \\
(82.40)\end{array}$ & $\begin{array}{l}7.59 \\
(228.40)\end{array}$ \\
\hline \multicolumn{6}{|c|}{$\begin{array}{l}P \text {-values are given for the differences between patients and controls. } P \text {-Values in bold means that } \\
\text { significant difference observed before the intervention are not significant after it, indicating some } \\
\text { return to normality. }{ }^{*} p<0.05 .{ }^{* *} p<0.001 \text {. ICC = Intraclass Correlation Coefficient. Cl: Confidence } \\
\text { Interval. SEM = Standard Error of Measurement. RSEM\%= Relative }(\%) \text { Standard Error of Measurement } \\
\text { expressed as a percentage. MDC = Minimal Detectable Change. \%RMDC = Relative (\%) Minimal } \\
\text { Detectable Change expressed as a percentage. Be careful not to confuse this ROM test (which is the } \\
\text { ROM reached during the DidRen laser test) and active ROM (performed by the patient before the } \\
\text { DidRen laser test). }\end{array}$} \\
\hline
\end{tabular}

Table 4 shows that after the intervention patients were significantly faster for average speed $\left(2.9^{\circ} \mathrm{s}^{-1} ; p<\right.$ $0.02)$, peak speed $\left(8.7^{\circ} s^{-1} ; p<0.011\right)$ and peak deceleration $\left(69.7^{\circ} s^{-2} ; p<0.007\right)$. Patients were significantly slower to reach peak speed $(0.01 \mathrm{~s} ; p<0.033)$ and peak acceleration $(0.01 \mathrm{~s} ; p<0.028)$. They took less time $(-0.01 \mathrm{~s} ; p<0.003)$ between peak acceleration and deceleration. Patients took less time to stabilize the laser into the target $(0.12 s ; p<0.026)$ and to perform the DidRen laser test $(4 s ; p<0.001)$. All difference values were smaller than the MDC (see Table 3).

ES observed for all kinematic variables ranged from low to medium (Table 4). The largest ES values were observed for DidRen total time, time between peak acceleration-deceleration, average speed and stabilisation time. 
Table 4

Results for kinematic variables during DidRen laser test for all patients (upper and lower spinal pain location) according to "before" and "after" the mobilizations.

\begin{tabular}{|c|c|c|c|c|c|}
\hline Variables & & $\begin{array}{l}\text { Mean (SD) or } \\
\text { Median } \\
(25 \%-75 \%)\end{array}$ & $\begin{array}{l}\text { Difference of } \\
\text { the means }\end{array}$ & $\begin{array}{l}\text { P-values } \\
(p<0.05)\end{array}$ & $\begin{array}{l}\text { Effect } \\
\text { Size }\end{array}$ \\
\hline \multirow[t]{2}{*}{ ROM test $\left({ }^{\circ}\right)$} & Before & $\begin{array}{l}27.01(27.94- \\
26.30)\end{array}$ & \multirow[t]{2}{*}{0.32} & \multirow[t]{2}{*}{0.486} & \multirow[t]{2}{*}{-0.14} \\
\hline & After & $\begin{array}{l}27.33(27.83- \\
26.77)\end{array}$ & & & \\
\hline \multirow[t]{2}{*}{ Average speed $\left({ }^{\circ} s^{-1}\right)$} & Before & $\begin{array}{l}42.36(34.88- \\
46.55)\end{array}$ & \multirow[t]{2}{*}{2.89} & \multirow[t]{2}{*}{$0.020 *$} & \multirow[t]{2}{*}{0.4} \\
\hline & After & $\begin{array}{l}45.26(38.62- \\
52.18)\end{array}$ & & & \\
\hline \multirow[t]{2}{*}{ Peak speed $\left({ }^{\circ} s^{-1}\right)$} & Before & $\begin{array}{l}88.06(79.70- \\
105.77)\end{array}$ & \multirow[t]{2}{*}{8.65} & \multirow[t]{2}{*}{$0.011 *$} & \multirow[t]{2}{*}{0.3} \\
\hline & After & $\begin{array}{l}96.70(88.47- \\
114.17)\end{array}$ & & & \\
\hline \multirow{2}{*}{$\begin{array}{l}\text { Peak acceleration } \\
\left({ }^{\circ} s^{-2}\right)\end{array}$} & Before & $\begin{array}{l}375.48(268.93- \\
493.27)\end{array}$ & \multirow[t]{2}{*}{26.32} & \multirow[t]{2}{*}{0.059} & \multirow[t]{2}{*}{0.2} \\
\hline & After & $\begin{array}{l}401.80(354.09- \\
600.22)\end{array}$ & & & \\
\hline \multirow[t]{2}{*}{ Peak deceleration $\left({ }^{\circ} s^{-2}\right)$} & Before & $\begin{array}{l}-630.62(-796.47- \\
517.58)\end{array}$ & \multirow[t]{2}{*}{69.74} & \multirow[t]{2}{*}{$0.007^{*}$} & \multirow[t]{2}{*}{-0.3} \\
\hline & After & $\begin{array}{l}-700.37(-915.70- \\
603.36)\end{array}$ & & & \\
\hline \multirow[t]{2}{*}{ Time to peak speed (s) } & Before & $0.12(0.10-0.16)$ & \multirow[t]{2}{*}{0.01} & \multirow[t]{2}{*}{$0.033^{*}$} & \multirow[t]{2}{*}{-0.3} \\
\hline & After & $0.11(0.10-0.13)$ & & & \\
\hline \multirow[t]{2}{*}{ Time to peak acceleration (s) } & Before & $0.19(0.17-0.24)$ & \multirow[t]{2}{*}{0.01} & \multirow[t]{2}{*}{$0.028 *$} & \multirow[t]{2}{*}{-0.3} \\
\hline & After & $0.19(0.16-0.21)$ & & & \\
\hline \multirow[t]{2}{*}{ Time to peak deceleration (s) } & Before & $\begin{array}{l}0.058(0.055- \\
0.081)\end{array}$ & \multirow[t]{2}{*}{0.0021} & \multirow[t]{2}{*}{0.750} & \multirow[t]{2}{*}{-0.1} \\
\hline & After & $\begin{array}{l}0.060(0.054- \\
0.071)\end{array}$ & & & \\
\hline \multirow{2}{*}{$\begin{array}{l}\text { Time between peaks } \\
\text { acceleration-deceleration (s) }\end{array}$} & Before & $-0.13(-0.15-0.11)$ & \multirow[t]{2}{*}{-0.01} & \multirow[t]{2}{*}{$0.003^{*}$} & \multirow[t]{2}{*}{0.5} \\
\hline & After & $-0.12(-0.14-0.10)$ & & & \\
\hline $\begin{array}{l}\text { Time from peak acceleration } \\
\text { to end of rotation (s) }\end{array}$ & Before & $0.15(0.13-0.18)$ & 0.01 & 0.182 & -0.2 \\
\hline
\end{tabular}




\begin{tabular}{|c|c|c|c|c|c|}
\hline Variables & & $\begin{array}{l}\text { Mean (SD) or } \\
\text { Median } \\
(25 \%-75 \%)\end{array}$ & $\begin{array}{l}\text { Difference of } \\
\text { the means }\end{array}$ & $\begin{array}{l}\text { P-values } \\
(p<0.05)\end{array}$ & $\begin{array}{l}\text { Effect } \\
\text { Size }\end{array}$ \\
\hline & After & $0.14(0.12-0.17)$ & & & \\
\hline \multirow[t]{2}{*}{ Angle at maximum speed $\left({ }^{\circ}\right)$} & Before & $\begin{array}{l}14.07(13.19- \\
14.96)\end{array}$ & 0.56 & 0.223 & 0.3 \\
\hline & After & $\begin{array}{l}14.63(13.84- \\
15.45)\end{array}$ & & & \\
\hline \multirow[t]{2}{*}{ Stabilization Time (s) } & Before & $1.96(0.37)$ & 0.12 & $0.026 *$ & -0.4 \\
\hline & After & $1.83(0.28)$ & & & \\
\hline \multirow[t]{2}{*}{ Overshoot $\left(^{\circ}\right)$} & Before & $0.71(0.26)$ & 0.06 & 0.270 & 0.2 \\
\hline & After & $0.65(0.22)$ & & & \\
\hline \multirow[t]{2}{*}{ DidRen total time (s) } & Before & $54.92(9.55)$ & 3.99 & $0.001 *$ & -0.5 \\
\hline & After & $50.93(7.33)$ & & & \\
\hline
\end{tabular}

If normality test passed results were in mean with standard deviation (SD) and if normality test failed results were in median with interquartile range (Q1-Q3). Before/After means before/after the mobilizations. $P$-values in bold means significant difference observed following the mobilizations. ${ }^{*} p<$ 0.05 .

\section{Discussion}

In accordance with our first hypothesis, the results confirm that kinematic performances during fast axial rotations of the head were significantly altered in patients with acute non-specific neck pain compared to significantly younger healthy controls. This discussion point regarding the age difference will be addressed within the limits of the study. However, our second hypothesis was not verified since no significant differences were observed between patients classified according to the pain location (i.e. suffering from pain in the cervical spinal upper levels as compared to those suffering in the lower levels). Our third hypothesis was also verified as after the reduction of pain observed after Maitland's passive accessory mobilizations of the neck, there was a significant effect on several kinematic parameters.

Moderate to excellent intra-individual reliability was observed for all kinematic variables except for overshoot, time to peak deceleration and time to peak acceleration to end of rotation. For average and peak speed our ICC values in healthy controls are in accordance with those computed by Sarig Bahat (2016) who established inter-tester reliability of similar kinematic measures using a virtual reality system in asymptomatic subjects [62]. In line with our observations, they also reported moderate reliability for rotation velocity, and good reliability for peak velocity [62]. 
The lower reliability results for overshoot, time to peak deceleration and time to peak acceleration to end of rotation variables can be partially explained by the fact that these kinematic parameters are more prone to a large variability among individuals. In our previous study [21], we calculated the reliability of the total time by performing the DidRen laser test twice. In the present study using a different methodology, good reliability of DidRen total time was observed but the ICC values observed (0.78) were slightly lower than our study of 2009 (0.93).

Here, we can conclude that intra-individual reliability of most computed kinematic variables is suitable and indicate that individuals would obtain similar measures when undergoing the DidRen laser test a second time.

Is the DidRen laser test more valid that other existing tests? It is difficult to answer this question because we have not included other tests in our protocol. The differences observed here in sensorimotor control performance of the neck between non-specific neck pain patients and healthy control subjects corroborate with previous observations in patients with acute and chronic neck pain patients $[18,63]$. Using a virtual environment to assess cervical kinematic measures, significant differences between chronic neck pain patients and healthy volunteers for Peak Velocity were found in both studies. However, our results are in contrast to de Zoete et al., who failed to observe differences in cervical sensorimotor control between individuals with chronic idiopathic neck pain and asymptomatic controls [64]. In de Zoete's study, tests were defined as sensorimotor because they challenged the proprioceptive system with the joint position error test, postural balance testing or visual system with the subjective visual vertical, smooth pursuit neck torsion or visual and vestibular systems with head-tilt response, the "Fly" or muscles endurance with the head-steadiness test. Of all these tests, only the "Fly", which measures the accuracy of the ability to follow a moving target but without a speed component, could be compared to our test.

With regard to our significant results, we can observe that pain could be responsible for the differences observed between patients and healthy controls. Three hypotheses could explain it. As first hypothesis, our test could have boosted the sensorimotor control of the neck via different sensorimotor channels that act together (i.e. neck, vestibular and ocular reflexes). During the DidRen laser test, the proprioception, the vestibular and the visuomotor control contribute concurrently to coordination of head and eye movement control to ensure performance [22]. So, the use of a non-specific test such as the DidRen laser can therefore lead to results that can be linked to a non-specific symptom such as pain. As second hypothesis, the principle of the DidRen laser test is in line with the Panjabi's theory and Riemann's definition of vertebral stability. The authors state that the various structures ensuring vertebral stability can be classified into interdependent systems: the passive, active and nervous systems $[24,65,66]$. According to Panjabi, the passive system consists of ligaments and joint capsule. The active and neural systems are the dynamic parts derived from the neuromotor control by feedforward and feedback of the spine muscles passing through the joint. In abnormal conditions, such as following trauma or degenerative process or even pain, the interaction of passive or/and active or/and neural systems can be disturbed and influence neck stabilization processes. Neck stabilization is more important in the neutral zone (i.e. the zone of high flexibility or laxity) which is located for one side axial rotation on $\mathrm{C}_{1}-\mathrm{C}_{2}$ from $0^{\circ}$ 
to $29.6^{\circ}$ [24]. Thus, with a mean head rotation amplitude of $27^{\circ}$ achieved by patients when performing the DidRen laser test we can assume that our test impacts more the neutral zone that could be perturbed by acute neck pain. As third hypothesis, sensorimotor performances could be integrated in the framework of decision-making: "reach the targets as fast as you can". Therefore, participants needed to adjust their speed during the dynamic phase and their accuracy during the stabilization phase in the axial rotation [67]. Speed-accuracy trade-off could be considered as a "signature" of the decision process [68]. This varies according to which motion behavior is emphasized: accuracy or speed [67] during, for instance, an aiming task that encompasses amplitude of the movement, the size and position of the target $[67,69$, 70]. Assessment of the speed-accuracy trade-off was not the goal of our study, but interestingly this trade-off is an underlying assumption which could interpret our results. Indeed, we showed that patients were slower to become as accurate (no significant difference in overshoots) as healthy controls. Moreover, our results show that the overshoot variable analysis is obviously representative of neck sensorimotor status quality and fits with the speed accuracy trade-off in the neutral zone [19, 23].

We have not been able to confirm our hypothesis that sensorimotor disturbances would be more important in participants with acute neck pain originating from upper cervical spinal levels $\left(C_{0}\right.$ to $\left.C_{2}\right)$ as was observed in patients with traumatic neck pain $[8,71]$. This could be explained by the sample size in upper $(n=17)$ and lower $(n=21)$ spinal pain groups that we might considered too small. Nevertheless, with a sample of patients comparable to the patients included in our study (upper $(n=21)$ and lower ( $n=$ 15) cervical spine pain groups), Treleaven et al. showed comparable results with a different sensorimotor test: the joint position error. A second reason may also be that the "axial rotation test" described by Satput et al (2019) [49] is not accurate enough and that some patients classified as upper cervical spine pain patients were not. During the follow-up, some patients classified as upper cervical spine pain patients were also relieved by therapy applied to the lower cervical spine levels. Perhaps, we could have chosen to select patients according to the cervical spine levels treated. If a patient was mobilized for more than $50 \%$ of the time at upper cervical levels, this patient could be classified as part of the upper cervical group.

To assess pain-related sensorimotor control changes, we chose passive manual mobilizations known to decrease neck pain [37]. Our results showed that manual mobilizations improved sensorimotor kinematic parameters as well. Our results are in accordance with other studies that showed more accurate processing of proprioceptive input is enhanced by reducing the effect of pain $[72,73]$. Additionally, a hypothetical explanation could be that sensorimotor control does not evolve according to the same improvement curve as patient's pain.

For significant kinematic variables between before and after intervention, ES range from low to medium. Our ES obtained after 6 weeks of passive mobilizations can be compared to the ES obtained by Meisingset et al. after 8 weeks of physiotherapy consisting of a wide range of modalities assessed by the Fly test [31]. Results must be interpreted with caution. The SEM is considered as an absolute index of reliability and can be used to determine the minimum difference to be considered as "real" [59]. The SEM can be seen as the measurement error at one moment in time and quantifies the precision of individual scores on a test. The reliability of the measure is found through significant differences between healthy 
controls and patients which are greater than SEM for DidRen laser total time and five kinematic parameters. Given the overlap between individuals with and without neck pain, the quality of movement was not decreased for every patient (see supplemental Table 3). This shows the great variability of the results, which is probably linked to the heterogeneity of this pathology. Nevertheless, in view of the results of the SEM, discrimination between patients with acute non-specific neck pain and asymptomatic individuals can be considered. The MDC, for its part, represents the measurement error that applies to two measurements in time [59]. So, if the measurements exceed the MDC, it is because something happens, and if patients are tested, this could be considered relevant. For example, for peak speed, the SEM was 36 $\%$ of the MDC. This result is in accordance with Bahat et al. who showed that the SEM was $37 \%$ of the MDC for right rotation and $36 \%$ for left rotation [62]. Between pre- and post- intervention, we showed that all significant results were below the MDC. We could explain this by the fact that our test did not challenge performance enough to reduce data variability. It could discriminate acute non-specific neck pain patients from asymptomatic individuals but not enough to be clinically relevant.

In view of the foregoing, clinicians could gain relevant insight on sensorimotor control by evaluating head-neck complex rotational movements as part of their assessment. This highlights the interest in the diagnostic process to discriminate acute non-specific neck pain patients from asymptomatic individuals to determine a cut-off point, which can be clinically relevant.

The results of the present study should be seen in the light of some methodological limitations.

While this prospective study provides interesting results, it should be confirmed in a study with a longer follow-up period.

The selection of an appropriate control group is essential $[74,75]$. As causal inference of a control group may be confounded by several (as yet unknown) clinical biases including age and the fact that a patient over the age of 50 is likely to still have residual effects on the neck of previous pain, it is possible that factors other than those studied may be responsible for the observed associations [76]. This explains the reason for matching our control group both biomechanically and clinically to our intervention group. This led us to exclude twelve control participants, with an average age of 40 years. They were excluded because they reported pain during the clinical examination (PAIVM's). Nevertheless, we made sure that our current control group was comparable to the normative biomechanical data of Hage et al [23]. Indeed, our current group showed the same results as Hage et al [23] and we were able to consider our current control group as a full-fledged control group. Based on this argument we called our "control group" "healthy" control group.

Due to the sample size, this study could be considered as a pilot trial. Future research with more diverse ethnic's background could be done to increase the external validity of the findings. Moreover, a relatively larger sample size could have been more representative.

There may have been a bias with patient's recruitment. Indeed, patients were referred to an experienced orthopaedic manual physiotherapist known as specialist in neck care. So, a multicentered study with 
different physiotherapists would have been methodologically more appropriate.

We have intentionally used an intervention that can modify the pain. This made our intervention nonspecific since pain is a heterogeneous variable which can occur with several functional disorders, such as a limited ROM [32]. Indeed, a more specific intervention would have altered the function more precisely and could have interfered with the functional aspect of the test.

Results related to the effect of pain reduction may also be related to the learning impact of the test. However, Bootsma et al. [77] showed that task difficulty affects motor performance but does not affect learning. Therefore, the learning effect can be assumed to be minor. This should be studied in future experiments.

The strength of this study is that for the first time a sensorimotor assessment of acute non-specific neck pain patients with a pragmatic intervention and follow up test immediately after the intervention has been completed.

\section{Conclusions}

The DidRen laser test demonstrated altered kinematic performances in a sample of Belgian patients suffering from acute neck pain compared to healthy participants. Contrary to our initial hypothesis, no differences in sensorimotor control are present when comparing patients with upper versus lower cervical spine pain levels. Finally, pain decrease observed after Maitland's passive neck mobilizations resulted in statistically but not clinically significant effect on many kinematic parameters. These results suggest that sensorimotor changes could occur rapidly after pain decrease. The present study is of importance because, to our knowledge, previous sensorimotor control studies only included chronic non-specific neck pain populations and it is the first study assessing neck sensorimotor control in acute non-specific neck pain patients.

\section{Declarations}

\section{Ethics approval and consent to participate}

All participants signed an informed consent. The study was approved by the Comité Académique de Bioéthique (Brussels, B200-2018-103) and conducted in accordance with the declaration of Helsinki.

\section{Consent for publication}

Renaud Hage (participant for fig. 2c) declares his consent to the publication of identifying information/images in BMC (open access online publication).

\section{Availability of data and materials}


All data generated or analyzed during this study are included in this published article [and its supplementary information files].

\section{Competing interests}

The authors declare that they have no competing interests.

\section{Funding}

Dr Frédérick Dierick and Dr Renaud Hage acknowledge financial support from the INTERREG Project FWVI n० 4.7.360.

\section{Authors' contributions}

All authors conceived the study. Formal analysis was done by RH, FD, CD. Methodology was done by RH, LP, NR, JMB, CD and FD. Validation of the data was done by RH, CD and FD. RH Selected the patients. Writing - original draft: RH. Writing - review \& editing was done by all authors.

\section{Acknowledgements}

Authors' want to thanks all patients and participants of this study.

\section{References}

1. Fejer R, Kyvik KO, Hartvigsen J. The prevalence of neck pain in the world population: a systematic critical review of the literature. Eur Spine J. 2006;15(6):834-48. Epub 2005/07/07. doi: 10.1007/s00586-004-0864-4. PubMed PMID: 15999284; PubMed Central PMCID: PMCPMC3489448.

2. Hoy DG, Protani M, De R, Buchbinder R. The epidemiology of neck pain. Best Pract Res Clin Rheumatol. 2010;24(6):783-92. Epub 2011/06/15. doi: 10.1016/j.berh.2011.01.019. PubMed PMID: 21665126.

3. Vos T, Barber RM, Bell B, Bertozzi-Villa A, Biryukov S, Bolliger I, et al. Global, regional, and national incidence, prevalence, and years lived with disability for 301 acute and chronic diseases and injuries in 188 countries, 1990-2013: a systematic analysis for the Global Burden of Disease Study 2013. The Lancet. 2015;386(9995):743-800. doi: 10.1016/s0140-6736(15)60692-4.

4. Blanpied PR, Gross AR, Elliott JM, Devaney LL, Clewley D, Walton DM, et al. Neck Pain: Revision 2017. J Orthop Sports Phys Ther. 2017;47(7):A1-a83. Epub 2017/07/02. doi: 10.2519/jospt.2017.0302. PubMed PMID: 28666405.

5. Childs JD, Cleland JA, Elliott JM, Teyhen DS, Wainner RS, Whitman JM, et al. Neck pain: Clinical practice guidelines linked to the International Classification of Functioning, Disability, and Health 
from the Orthopedic Section of the American Physical Therapy Association. J Orthop Sports Phys Ther. 2008;38(9):A1-a34. Epub 2008/09/02. doi: 10.2519/jospt.2008.0303. PubMed PMID: 18758050 .

6. Coulter ID, Crawford C, Vernon H, Hurwitz EL, Khorsan R, Booth MS, et al. Manipulation and Mobilization for Treating Chronic Nonspecific Neck Pain: A Systematic Review and Meta-Analysis for an Appropriateness Panel. Pain physician. 2019;22(2):E55-e70. Epub 2019/03/30. PubMed PMID: 30921975.

7. Childs JD, Fritz JM, Piva SR, Whitman JM. Proposal of a classification system for patients with neck pain. J Orthop Sports Phys Ther. 2004;34(11):686-96; discussion 97-700. Epub 2004/12/22. doi: 10.2519/jospt.2004.34.11.686. PubMed PMID: 15609489.

8. Kristjansson E, Treleaven J. Sensorimotor function and dizziness in neck pain: implications for assessment and management. J Orthop Sports Phys Ther. 2009;39(5):364-77. Epub 2009/05/05. doi: 10.2519/jospt.2009.2834. PubMed PMID: 19411769.

9. Treleaven J. Sensorimotor disturbances in neck disorders affecting postural stability, head and eye movement control. Man Ther. 2008;13(1):2-11. Epub 2007/08/19. doi: 10.1016/j.math.2007.06.003. PubMed PMID: 17702636.

10. Bogduk N. On cervical zygapophysial joint pain after whiplash. Spine (Phila Pa 1976). 2011;36(25 Suppl):S194-9. Epub 2011/10/25. doi: 10.1097/BRS.0b013e3182387f1d. PubMed PMID: 22020612.

11. Lee H, Nicholson LL, Adams RD. Cervical range of motion associations with subclinical neck pain. Spine (Phila Pa 1976). 2004;29(1):33-40. Epub 2003/12/31. doi: 10.1097/01.Brs.0000103944.10408.Ba. PubMed PMID: 14699273.

12. Rudolfsson T, Bjorklund M, Djupsjobacka M. Range of motion in the upper and lower cervical spine in people with chronic neck pain. Man Ther. 2012;17(1):53-9. Epub 2011/09/29. doi: 10.1016/j.math.2011.08.007. PubMed PMID: 21945295.

13. Roijezon U, Djupsjobacka M, Bjorklund M, Hager-Ross C, Grip H, Liebermann DG. Kinematics of fast cervical rotations in persons with chronic neck pain: a cross-sectional and reliability study. BMC Musculoskelet Disord. 2010;11:222. Epub 2010/09/30. doi: 10.1186/1471-2474-11-222. PubMed PMID: 20875135; PubMed Central PMCID: PMCPMC3224737.

14. Roijezon U, Clark NC, Treleaven J. Proprioception in musculoskeletal rehabilitation. Part 1: Basic science and principles of assessment and clinical interventions. Man Ther. 2015;20(3):368-77. Epub 2015/02/24. doi: 10.1016/j.math.2015.01.008. PubMed PMID: 25703454.

15. Sarig Bahat $H$, Weiss $P L$, Sprecher E, Krasovsky A, Laufer Y. Do neck kinematics correlate with pain intensity, neck disability or with fear of motion? Man Ther. 2014;19(3):252-8. Epub 2013/12/03. doi: 10.1016/j.math.2013.10.006.

16. Dugailly PM, Coucke A, Salem W, Feipel V. Assessment of cervical stiffness in axial rotation among chronic neck pain patients: A trial in the framework of a non-manipulative osteopathic management. Clin Biomech (Bristol, Avon). 2018;53:65-71. Epub 2018/02/18. doi:

10.1016/j.clinbiomech.2018.02.005. PubMed PMID: 29454150. 
17. Sarig Bahat $H$, Weiss $P L$, Laufer $Y$. Neck pain assessment in a virtual environment. Spine (Phila Pa 1976). 2010;35(4):E105-12. Epub 2010/01/30. doi: 10.1097/BRS.0b013e3181b79358. PubMed PMID: 20110842.

18. Sarig Bahat H, Chen X, Reznik D, Kodesh E, Treleaven J. Interactive cervical motion kinematics: sensitivity, specificity and clinically significant values for identifying kinematic impairments in patients with chronic neck pain. Man Ther. 2015;20(2):295-302. Epub 2014/12/03. doi: 10.1016/j.math.2014.10.002. PubMed PMID: 25456272.

19. Kristjansson E, Hardardottir L, Asmundardottir M, Gudmundsson K. A new clinical test for cervicocephalic kinesthetic sensibility: "the fly". Arch Phys Med Rehabil. 2004;85(3):490-5. Epub 2004/03/20. PubMed PMID: 15031839.

20. Revel M, Andre-Deshays $C$, Minguet M. Cervicocephalic kinesthetic sensibility in patients with cervical pain. Arch Phys Med Rehabil. 1991;72(5):288-91. Epub 1991/04/01. PubMed PMID: 2009044.

21. Hage R, Ancenay E. Identification of a relationship between cervical spine function and rotational movement control. Ann Phys Rehabil Med. 2009;52(9):653-67. Epub 2009/09/29. doi:

10.1016/j.rehab.2009.04.003. PubMed PMID: 19783494.

22. Hage R, Buisseret F, Pitance L, Brismee JM, Detrembleur C, Dierick F. Head-neck rotational movements using DidRen laser test indicate children and seniors' lower performance. PLoS One. 2019;14(7):e0219515. Epub 2019/07/26. doi: 10.1371/journal.pone.0219515. PubMed PMID: 31344044.

23. Hage R, Dierick F, Roussel N, Pitance L, Detrembleur C. Age-related kinematic performance should be considered during fast head-neck rotation target task in individuals aged from 8 to 85 years old. PeerJ. 2019;7. doi: 10.7717/peerj.7095.

24. Panjabi MM. The stabilizing system of the spine. Part II. Neutral zone and instability hypothesis. J Spinal Disord. 1992;5(4):390-6; discussion 7. Epub 1992/12/01. doi: 10.1097/00002517199212000-00002. PubMed PMID: 1490035.

25. Dugailly PM, De Santis R, Tits M, Sobczak S, Vigne A, Feipel V. Head repositioning accuracy in patients with neck pain and asymptomatic subjects: concurrent validity, influence of motion speed, motion direction and target distance. Eur Spine J. 2015;24(12):2885-91. Epub 2015/10/07. doi: 10.1007/s00586-015-4263-9. PubMed PMID: 26438174.

26. Penning L, Wilmink JT. Rotation of the cervical spine. A CT study in normal subjects. Spine (Phila Pa 1976). 1987;12(8):732-8. Epub 1987/10/01. doi: 10.1097/00007632-198710000-00003. PubMed PMID: 3686228.

27. de Zoete RM, Osmotherly PG, Rivett DA, Farrell SF, Snodgrass SJ. Sensorimotor control in individuals with idiopathic neck pain and healthy individuals: A systematic review and meta-analysis. Arch Phys Med Rehabil. 2016. Epub 2016/10/25. doi: 10.1016/j.apmr.2016.09.121. PubMed PMID: 27771360.

28. Michiels S, De Hertogh W, Truijen S, November D, Wuyts F, Van de Heyning P. The assessment of cervical sensory motor control: a systematic review focusing on measuring methods and their 
clinimetric characteristics. Gait Posture. 2013;38(1):1-7. Epub 2012/11/17. doi:

10.1016/j.gaitpost.2012.10.007. PubMed PMID: 23153836.

29. de Zoete RMJ, Osmotherly PG, Rivett DA, Snodgrass SJ. Cervical Sensorimotor Control Does Not Change Over Time and Is Not Related to Chronic Idiopathic Neck Pain Characteristics: A 6-Month Longitudinal Observational Study. Phys Ther. 2020;100(2):268-82. Epub 2020/02/08. doi: 10.1093/ptj/pzz167. PubMed PMID: 32031655.

30. Haavik H, Murphy $B$. The role of spinal manipulation in addressing disordered sensorimotor integration and altered motor control. J Electromyogr Kinesiol. 2012;22(5):768-76. Epub 2012/04/10. doi: 10.1016/j.jelekin.2012.02.012. PubMed PMID: 22483612.

31. Meisingset I, Stensdotter AK, Woodhouse A, Vasseljen O. Neck motion, motor control, pain and disability: A longitudinal study of associations in neck pain patients in physiotherapy treatment. Man Ther. 2016;22:94-100. Epub 2015/11/21. doi: 10.1016/j.math.2015.10.013. PubMed PMID: 26586133.

32. Bialosky JE, Beneciuk JM, Bishop MD, Coronado RA, Penza CW, Simon CB, et al. Unraveling the Mechanisms of Manual Therapy: Modeling an Approach. J Orthop Sports Phys Ther. 2018;48(1):818. Epub 2017/10/17. doi: 10.2519/jospt.2018.7476. PubMed PMID: 29034802.

33. Bialosky JE, Bishop MD, Price DD, Robinson ME, George SZ. The mechanisms of manual therapy in the treatment of musculoskeletal pain: a comprehensive model. Man Ther. 2009;14(5):531-8. Epub 2008/11/26. doi: 10.1016/j.math.2008.09.001. PubMed PMID: 19027342; PubMed Central PMCID: PMCPMC2775050.

34. Reid SA, Rivett DA, Katekar MG, Callister R. Comparison of mulligan sustained natural apophyseal glides and maitland mobilizations for treatment of cervicogenic dizziness: a randomized controlled trial. Phys Ther. 2014;94(4):466-76. Epub 2013/12/18. doi: 10.2522/ptj.20120483. PubMed PMID: 24336477.

35. Tuttle N, Barrett R, Laakso L. Relation between changes in posteroanterior stiffness and active range of movement of the cervical spine following manual therapy treatment. Spine (Phila Pa 1976). 2008;33(19):E673-9. Epub 2008/09/02. doi: 10.1097/BRS.0b013e31817f93f9. PubMed PMID: 18758348.

36. Tuttle N, Hazle C. Spinal PA movements behave 'as if' there are limitations of local segmental mobility and are large enough to be perceivable by manual palpation: A synthesis of the literature. Musculoskeletal Science and Practice. 2018;36:25-31. doi: 10.1016/j.msksp.2018.04.005.

37. Lee KS, Lee JH. Effect of maitland mobilization in cervical and thoracic spine and therapeutic exercise on functional impairment in individuals with chronic neck pain. J Phys Ther Sci. 2017;29(3):531-5. Epub 2017/03/31. doi: 10.1589/jpts.29.531. PubMed PMID: 28356648; PubMed Central PMCID: PMCPMC5361027.

38. Vernon H. The Neck Disability Index: state-of-the-art, 1991-2008. J Manipulative Physiol Ther. 2008;31(7):491-502. Epub 2008/09/23. doi: 10.1016/j.jmpt.2008.08.006. PubMed PMID: 18803999. 
39. Cleland JA, Childs JD, Whitman JM. Psychometric properties of the Neck Disability Index and Numeric Pain Rating Scale in patients with mechanical neck pain. Arch Phys Med Rehabil. 2008;89(1):69-74. Epub 2008/01/01. doi: 10.1016/j.apmr.2007.08.126. PubMed PMID: 18164333.

40. De Hertogh WJ, Vaes PH, Vijverman V, De Cordt A, Duquet W. The clinical examination of neck pain patients: the validity of a group of tests. Manual therapy. 2007;12(1):50-5.

41. Schneider GM, Jull G, Thomas K, Smith A, Emery C, Faris P, et al. Intrarater and interrater reliability of select clinical tests in patients referred for diagnostic facet joint blocks in the cervical spine. Arch Phys Med Rehabil. 2013;94(8):1628-34. Epub 2013/03/15. doi: 10.1016/j.apmr.2013.02.015. PubMed PMID: 23485344.

42. Schneider GM, Jull G, Thomas K, Smith A, Emery C, Faris P, et al. Derivation of a clinical decision guide in the diagnosis of cervical facet joint pain. Arch Phys Med Rehabil. 2014;95(9):1695-701. Epub 2014/03/26. doi: 10.1016/j.apmr.2014.02.026. PubMed PMID: 24662813.

43. Martel J, Dugas C, Lafond D, Descarreaux M. Validation of the French version of the Bournemouth Questionnaire. The Journal of the Canadian Chiropractic Association. 2009;53(2):102-20. Epub 2009/06/10. PubMed PMID: 19506700; PubMed Central PMCID: PMCPMC2686031.

44. Chaory K, Fayad F, Rannou F, Lefevre-Colau MM, Fermanian J, Revel M, et al. Validation of the French version of the fear avoidance belief questionnaire. Spine. 2004;29(8):908-13. Epub 2004/04/15. doi: 10.1097/00007632-200404150-00018. PubMed PMID: 15082995.

45. Vernon H, Mior S. The Neck Disability Index: a study of reliability and validity. J Manipulative Physiol Ther. 1991;14(7):409-15. Epub 1991/09/01. PubMed PMID: 1834753.

46. Cleland JA, Fritz JM, Childs JD. Psychometric properties of the Fear-Avoidance Beliefs Questionnaire and Tampa Scale of Kinesiophobia in patients with neck pain. Am J Phys Med Rehabil. 2008;87(2):109-17. Epub 2007/11/13. doi: 10.1097/PHM.0b013e31815b61f1. PubMed PMID: 17993982.

47. Hage R, Detrembleur C, Dierick F, Pitance L, Jojczyk L, Estievenart W, et al. DYSKIMOT: An Ultra-LowCost Inertial Sensor to Assess Head's Rotational Kinematics in Adults during the Didren-Laser Test. Sensors (Basel). 2020;20(3). Epub 2020/02/09. doi: 10.3390/s20030833. PubMed PMID: 32033169.

48. Grant T, Niere K. Techniques used by manipulative physiotherapists in the management of headaches. The Australian journal of physiotherapy. 2000;46(3):215-22. Epub 2001/10/26. doi: 10.1016/s0004-9514(14)60330-5. PubMed PMID: 11676805.

49. Satpute K, Nalband S, Hall T. The CO-C2 axial rotation test: normal values, intra- and inter-rater reliability and correlation with the flexion rotation test in normal subjects. J Man Manip Ther. 2019;27(2):92-8. Epub 2019/04/03. doi: 10.1080/10669817.2018.1533195. PubMed PMID: 30935342; PubMed Central PMCID: PMCPMC6484503.

50. Smedmark V, Wallin M, Arvidsson I. Inter-examiner reliability in assessing passive intervertebral motion of the cervical spine. Man Ther. 2000;5(2):97-101. Epub 2000/07/21. doi: 10.1054/math.2000.0234. 
51. Bogduk N, Mercer S. Biomechanics of the cervical spine. I: Normal kinematics. Clin Biomech (Bristol, Avon). 2000;15(9):633-48. Epub 2000/08/18. doi: 10.1016/s0268-0033(00)00034-6. PubMed PMID: 10946096.

52. Jull G, Treleaven J, Versace G. Manual examination: is pain provocation a major cue for spinal dysfunction? The Australian journal of physiotherapy. 1994;40(3):159-65. Epub 1994/01/01. doi: 10.1016/s0004-9514(14)60574-2. PubMed PMID: 25025431.

53. Uthaikhup S, Jull G. Performance in the cranio-cervical flexion test is altered in elderly subjects. Man Ther. 2009;14(5):475-9. Epub 2009/01/28. doi: 10.1016/j.math.2008.12.003. PubMed PMID: 19171497.

54. Williamson A, Hoggart B. Pain: a review of three commonly used pain rating scales. $J$ Clin Nurs. 2005;14(7):798-804. Epub 2005/07/08. doi: 10.1111/j.1365-2702.2005.01121.x. PubMed PMID: 16000093.

55. O'Leary S, Jull G, Kim M, Uthaikhup S, Vicenzino B. Training mode-dependent changes in motor performance in neck pain. Arch Phys Med Rehabil. 2012;93(7):1225-33. Epub 2012/05/01. doi: 10.1016/j.apmr.2012.02.018. PubMed PMID: 22542489.

56. Falla DL, Jull GA, Hodges PW. Patients with neck pain demonstrate reduced electromyographic activity of the deep cervical flexor muscles during performance of the craniocervical flexion test. Spine (Phila Pa 1976). 2004;29(19):2108-14. Epub 2004/09/30. doi:

10.1097/01.brs.0000141170.89317.0e. PubMed PMID: 15454700.

57. Reid D, Rebbeck T, McCarthy C. Clinical reasoning for complex cervical spine conditions. International Journal of Osteopathic Medicine. 2018;27:45-51. doi: 10.1016/j.ijosm.2017.09.002.

58. Shrout PE. Measurement reliability and agreement in psychiatry. Statistical methods in medical research. 1998;7(3):301 - 17. Epub 1998/11/06. doi: 10.1177/096228029800700306. PubMed PMID: 9803527.

59. Weir JP. Quantifying test-retest reliability using the intraclass correlation coefficient and the SEM. Journal of strength and conditioning research. 2005;19(1):231-40. Epub 2005/02/12. doi: 10.1519/15184.1. PubMed PMID: 15705040.

60. Swait G, Rushton AB, Miall RC, Newell D. Evaluation of cervical proprioceptive function: optimizing protocols and comparison between tests in normal subjects. Spine (Phila Pa 1976). 2007;32(24):E692-701. Epub 2007/11/17. doi: 10.1097/BRS.0b013e31815a5a1b. PubMed PMID: 18007229.

61. Fritz CO, Morris PE, Richler JJ. Effect size estimates: current use, calculations, and interpretation. J Exp Psychol Gen. 2012;141(1):2-18. Epub 2011/08/10. doi: 10.1037/a0024338. PubMed PMID: 21823805.

62. Sarig Bahat H, Sprecher E, Sela I, Treleaven J. Neck motion kinematics: an inter-tester reliability study using an interactive neck VR assessment in asymptomatic individuals. Eur Spine J. 2016. Epub 2016/02/03. doi: 10.1007/s00586-016-4388-5. PubMed PMID: 26831536. 
63. Meisingset I, Woodhouse A, Stensdotter AK, Stavdahl O, Loras H, Gismervik S, et al. Evidence for a general stiffening motor control pattern in neck pain: a cross sectional study. BMC Musculoskelet Disord. 2015;16:56. Epub 2015/04/19. doi: 10.1186/s12891-015-0517-2. PubMed PMID: 25888215; PubMed Central PMCID: PMCPMC4377005.

64. de Zoete RMJ, Osmotherly PG, Rivett DA, Snodgrass SJ. No Differences Between Individuals With Chronic Idiopathic Neck Pain and Asymptomatic Individuals on 7 Cervical Sensorimotor Control Tests: A Cross-sectional Study. J Orthop Sports Phys Ther. 2020;50(1):33-43. Epub 2020/01/02. doi: 10.2519/jospt.2020.8846. PubMed PMID: 31892290.

65. Riemann BL, Lephart SM. The sensorimotor system, part I: the physiologic basis of functional joint stability. J AthI Train. 2002;37(1):71-9. Epub 2006/03/25. PubMed PMID: 16558670; PubMed Central PMCID: PMCPMC164311.

66. Panjabi MM. The stabilizing system of the spine. Part I. Function, dysfunction, adaptation, and enhancement. J Spinal Disord. 1992;5(4):383-9; discussion 97. Epub 1992/12/01. doi: 10.1097/00002517-199212000-00001. PubMed PMID: 1490034.

67. Zhang J, Rowe JB. Dissociable mechanisms of speed-accuracy tradeoff during visual perceptual learning are revealed by a hierarchical drift-diffusion model. Front Neurosci. 2014;8:69. Epub 2014/05/02. doi: 10.3389/fnins.2014.00069. PubMed PMID: 24782701; PubMed Central PMCID: PMCPMC3988401.

68. Heitz RP. The speed-accuracy tradeoff: history, physiology, methodology, and behavior. Front Neurosci. 2014;8:150. Epub 2014/06/27. doi: 10.3389/fnins.2014.00150. PubMed PMID: 24966810; PubMed Central PMCID: PMCPMC4052662.

69. Descarreaux M, Passmore SR, Cantin V. Head movement kinematics during rapid aiming task performance in healthy and neck-pain participants: the importance of optimal task difficulty. Man Ther. 2010;15(5):445-50. Epub 2010/06/29. doi: 10.1016/j.math.2010.02.009. PubMed PMID: 20579929.

70. Passmore SR, Burke JR, Good C, Lyons JL, Dunn AS. Spinal manipulation impacts cervical spine movement and fitts' task performance: a single-blind randomized before-after trial. J Manipulative Physiol Ther. 2010;33(3):189-92. Epub 2010/03/31. doi: 10.1016/j.jmpt.2010.01.007. PubMed PMID: 20350671.

71. Treleaven J, Clamaron-Cheers C, Jull G. Does the region of pain influence the presence of sensorimotor disturbances in neck pain disorders? Man Ther. 2011;16(6):636-40. Epub 2011/09/06. doi: 10.1016/j.math.2011.07.008. PubMed PMID: 21890397.

72. Haavik H, Murphy B. Subclinical neck pain and the effects of cervical manipulation on elbow joint position sense. J Manipulative Physiol Ther. 2011;34(2):88-97. Epub 2011/02/22. doi: 10.1016/j.jmpt.2010.12.009. PubMed PMID: 21334540.

73. Palmgren PJ, Sandstrom PJ, Lundqvist FJ, Heikkila H. Improvement after chiropractic care in cervicocephalic kinesthetic sensibility and subjective pain intensity in patients with nontraumatic 
chronic neck pain. J Manipulative Physiol Ther. 2006;29(2):100-6. Epub 2006/02/08. doi: 10.1016/j.jmpt.2005.12.002. PubMed PMID: 16461168.

74. Mansournia MA, Jewell NP, Greenland S. Case-control matching: effects, misconceptions, and recommendations. Eur J Epidemiol. 2018;33(1):5-14. Epub 2017/11/05. doi: 10.1007/s10654-0170325-0. PubMed PMID: 29101596.

75. Verani JR, Baqui AH, Broome CV, Cherian T, Cohen C, Farrar JL, et al. Case-control vaccine effectiveness studies: Preparation, design, and enrollment of cases and controls. Vaccine. 2017;35(25):3295-302. Epub 2017/04/27. doi: 10.1016/j.vaccine.2017.04.037. PubMed PMID: 28442231; PubMed Central PMCID: PMCPMC7007298.

76. Sasieni P, Castanon A, Cuzick J. Effectiveness of cervical screening with age: population based casecontrol study of prospectively recorded data. Bmj. 2009;339:b2968. Epub 2009/07/30. doi: 10.1136/bmj.b2968. PubMed PMID: 19638651; PubMed Central PMCID: PMCPMC2718082.

77. Bootsma JM, Hortobagyi T, Rothwell JC, Caljouw SR. The Role of Task Difficulty in Learning a Visuomotor Skill. Med Sci Sports Exerc. 2018;50(9):1842-9. Epub 2018/04/11. doi: 10.1249/MSS.0000000000001635. PubMed PMID: 29634641.

\section{Figures}




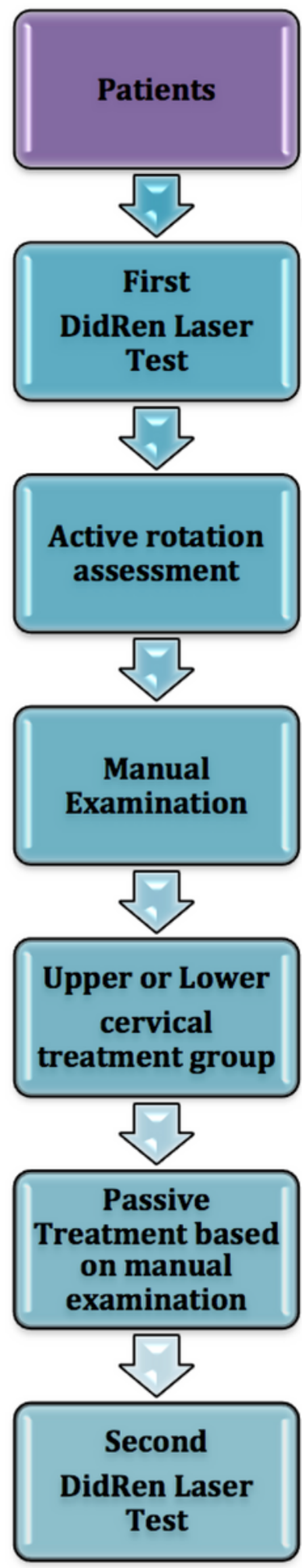

Inclusion:

(1) neck pain (NDI $>8 \%$, NPRS $>3$ )

(2) (<3months) non-specific neck pain

Exclusion:

(1) History of neck surgery,

(2) Dizziness caused by neck or head movements,

(3) Cervical radiculopathy diagnosed by a physician

Inclusion:

No neck pain (NDI< $8 \%, \mathrm{NPRS}=0$ )

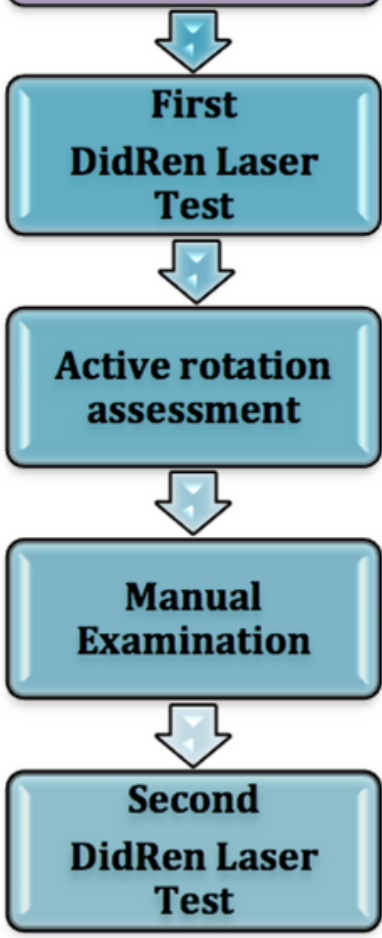

Exclusion:

(1) Neck complaints during past year

(2) Radiating symptoms in the shoulder or arm region

(3) Headaches

(4) History of neck trauma or were treated for spinal disorder

(5) If pain can be identify based on the cervical rotation ROM procedure and/or manual examination

\section{Figure 1}

Flow chart. Flow chart of the inclusion of patients and healthy controls. Neck Disability Index= NDI. Numerical Pain Rating Scale=NPRS. Range of Motion=ROM. 


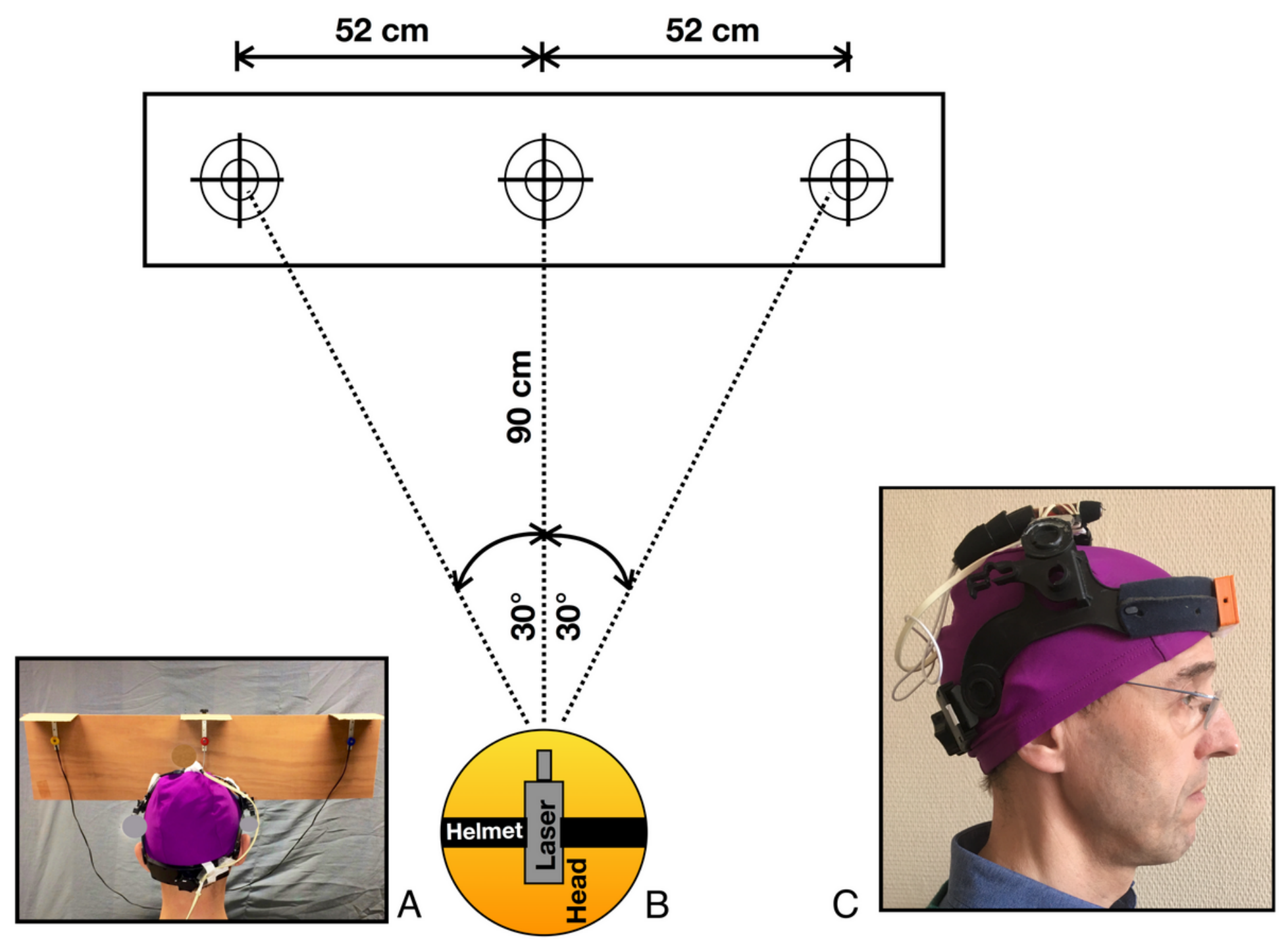

Figure 2

Installation of the DidRen laser test. (A) Head position in front of targets. (B) Schematic diagram view from above of the experimental setup with the three photodetectors. (C) Helmet worn by the participant with laser on the top and DYSKIMOT on the forehead. 

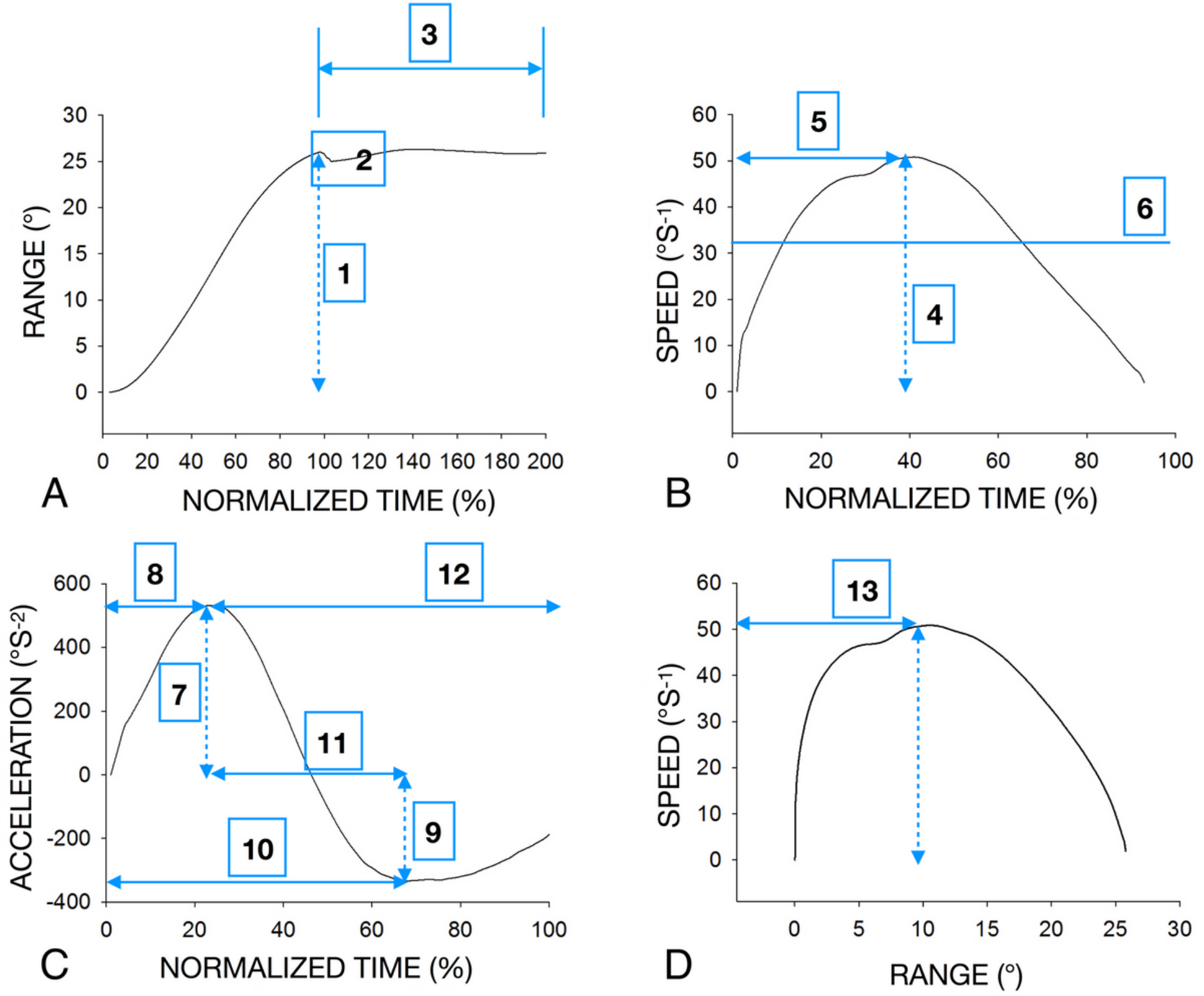

Figure 3

Typical plots of variables analyzed during one right rotation in a participant of the Younger adult's group (age: 22 yrs, sex: female). All values are in absolute value. (A) (1) range of motion during the test (ROM test in $\left.{ }^{\circ}\right)$; (2) overshoot ( $\left.{ }^{\circ} \mathrm{s}-1\right)$; (3) stabilization time (s); (4) peak speed ( $\mathrm{s}-1$ ); (B) (5) time to peak speed (s); (6) average speed ( $\left.{ }^{\circ} \mathrm{s}-1\right)$; (7) peak acceleration ( $\left.\mathrm{s}-2\right)$; (C) (8) time to peak acceleration (s); (9) peak deceleration ( $s-2) ;(10)$ time to peak deceleration (s); (11) time between peaks of acceleration and deceleration (s); (12) time from peak acceleration to end of rotation (s); (D) (13) angle at maximum speed $\left({ }^{\circ}\right)$. 


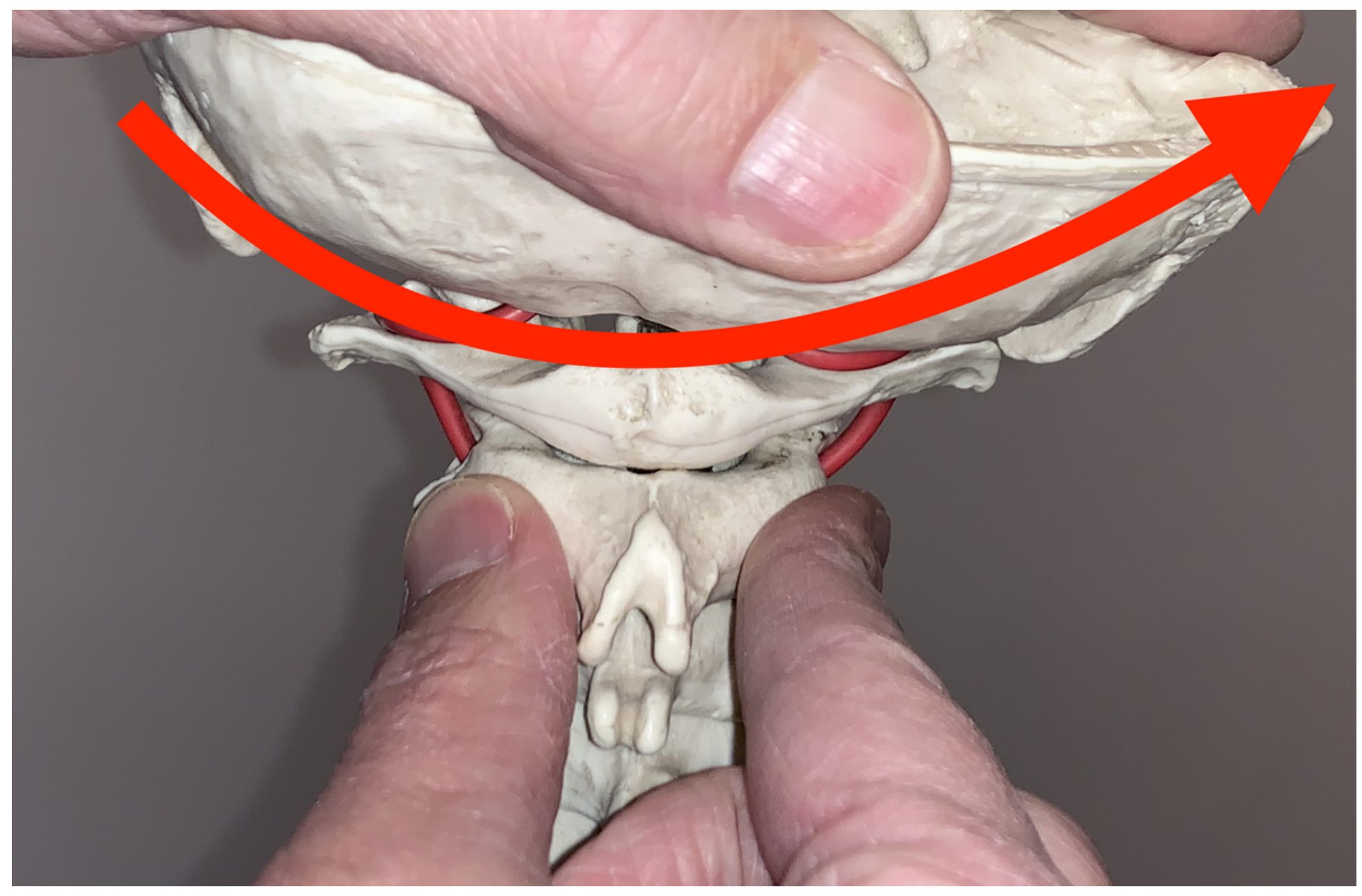

\section{Figure 4}

Example of $\mathrm{C} 0-\mathrm{C} 2$ axial rotation test to the left (posterior view). The patient was examined in a standardized sitting position with the neck in neutral position. The assessor passively rotated the patient's head to the left with C2 stabilized and the assessor's thumb and index fingers to isolate superior cervical levels from below. 

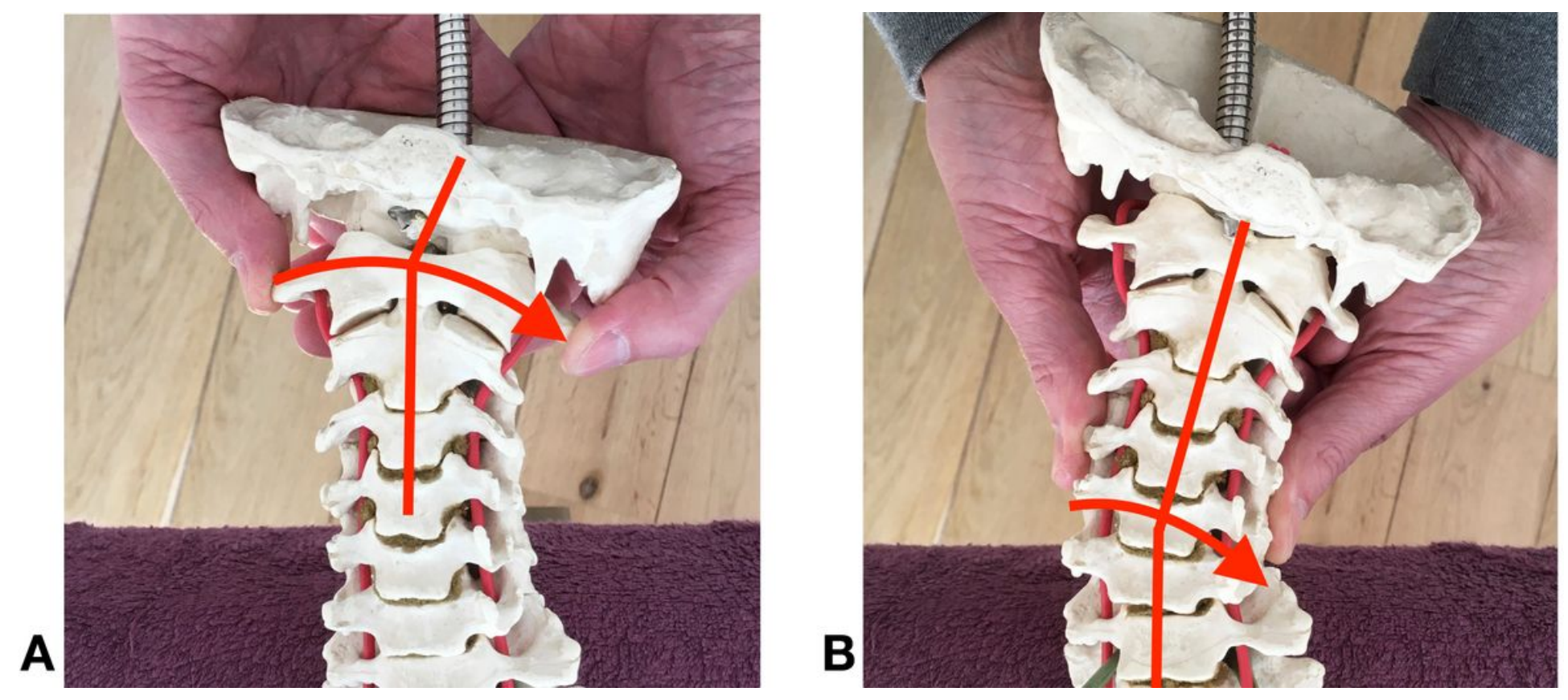

Figure 5

Examples of PPIVM's (Passive Physiological Intervertebral Movement's) in Lateral flexion. Lateral flexion to the left on $\mathrm{C} 1$ (A) and C5 (B) with hand placement ("patient" in supine with the "head" beyond the end of the couch). With both hands, the assessor gave support under the occiput. The assessor applied the thumbs directed laterally to the articular pillars from the upper cervical region $\mathrm{C} 1(\mathrm{~A})$ to the lower region C5 (B) on each side.

A
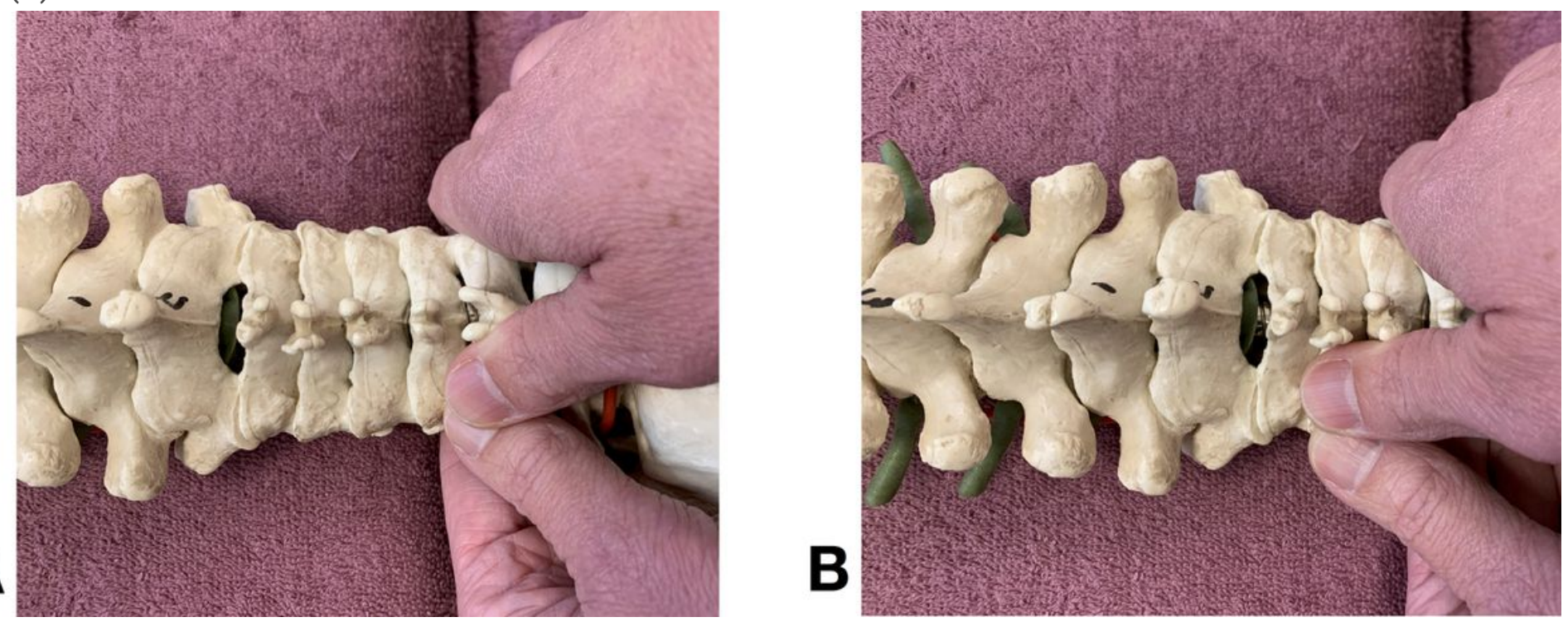

Figure 6

Examples of PAIVM's (Passive Accessory Intervertebral Movement's). Right unilateral on C2 (A) and C6 (B) with hand placement ("patient" in prone with the "head" on the right side of each picture). The assessor applied his thumb directed posterior-anterior force to the articular pillars from the upper cervical region $\mathrm{C} 0-1, \mathrm{C} 1-2$ and $\mathrm{C} 2-3$ to the lower region $\mathrm{C} 6-7$ on each side. 


\section{Supplementary Files}

This is a list of supplementary files associated with this preprint. Click to download.

- SupplementalTable1.docx

- SupplementalTable2.docx

- SupplementalTable3.docx

- RawDataHage.xlsx 